Review article

\title{
Insights on the pathophysiology of Alzheimer's disease: The crosstalk between amyloid pathology, neuroinflammation and the peripheral immune system
}

\author{
Sandro Dá Mesquita ${ }^{a, b}$, Ana Catarina Ferreira ${ }^{a, b}$, João Carlos Sousa ${ }^{a, b}$, \\ Margarida Correia-Neves ${ }^{\mathrm{a}, \mathrm{b}}$, Nuno Sousa ${ }^{\mathrm{a}, \mathrm{b}}$, Fernanda Marques ${ }^{\mathrm{a}, \mathrm{b}, *}$ \\ a Life and Health Sciences Research Institute (ICVS), School of Health Sciences, University of Minho, Campus Gualtar, 4710-057 Braga, Portugal \\ b ICVS/3B's - PT Government Associate Laboratory, Braga, Guimaraes, Portugal
}

\section{A R T I C L E I N F O}

\section{Article history:}

Received 7 January 2016

Received in revised form 9 June 2016

Accepted 14 June 2016

Available online 18 June 2016

\section{Keywords:}

Alzheimer's disease

Aging

Amyloid beta

Cognition

Blood-brain barrier

Choroid plexus

Cerebrospinal fluid

Glial cells

Neurons

Cytokines

Neuroinflammation

Immune system

\begin{abstract}
A B S T R A C T
Alzheimer's disease (AD) is the most common form of dementia, whose prevalence is growing along with the increased life expectancy. Although the accumulation and deposition of amyloid beta $(A \beta)$ peptides in the brain is viewed as one of the pathological hallmarks of $A D$ and underlies, at least in part, brain cell dysfunction and behavior alterations, the etiology of this neurodegenerative disease is still poorly understood. Noticeably, increased amyloid load is accompanied by marked inflammatory alterations, both at the level of the brain parenchyma and at the barriers of the brain. However, it is debatable whether the neuroinflammation observed in aging and in $\mathrm{AD}$, together with alterations in the peripheral immune system, are responsible for increased amyloidogenesis, decreased clearance of $A \beta$ out of the brain and/or the marked deficits in memory and cognition manifested by AD patients. Herein, we scrutinize some important traits of the pathophysiology of aging and $\mathrm{AD}$, focusing on the interplay between the amyloidogenic pathway, neuroinflammation and the peripheral immune system.
\end{abstract}

(C) 2016 Elsevier Ltd. All rights reserved.

\section{Contents}

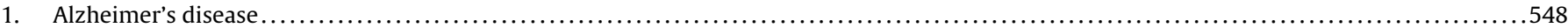

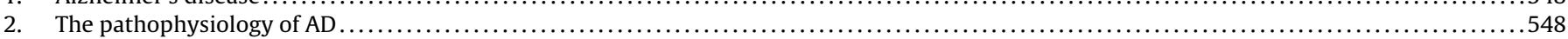

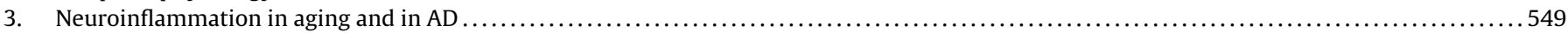

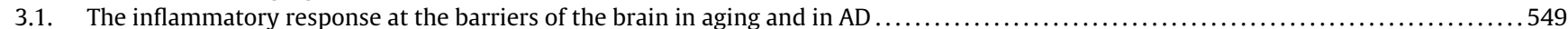

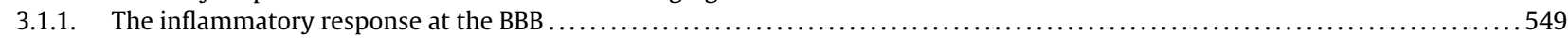

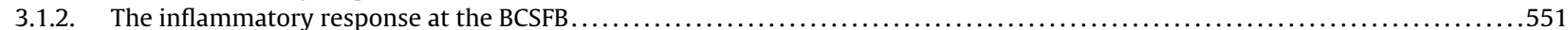

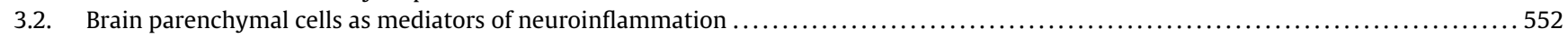

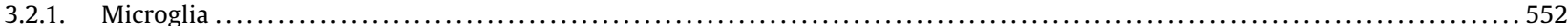

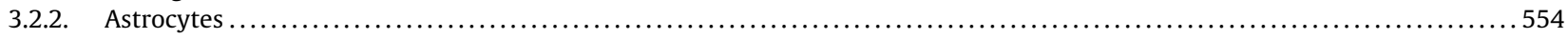

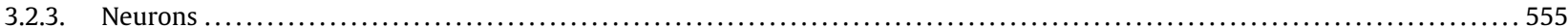

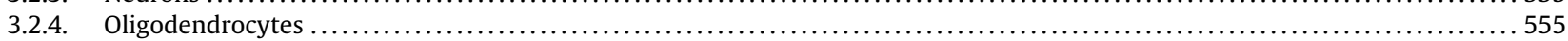

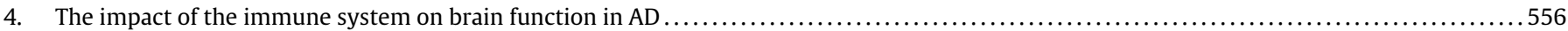

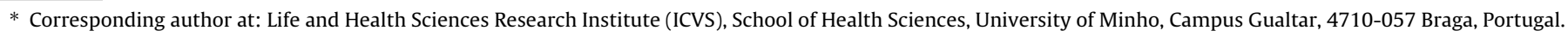
E-mail address: fmarques@ecsaude.uminho.pt (F. Marques).
} 


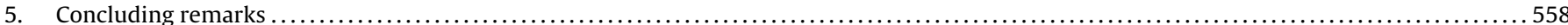

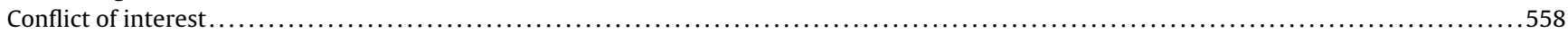

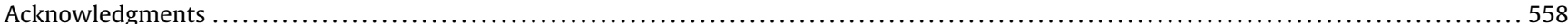

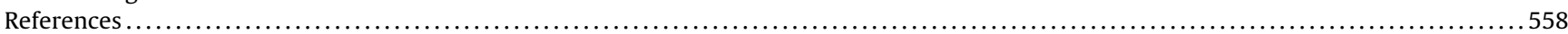

\section{Alzheimer's disease}

Alzheimer's disease (AD) is the most prevalent form of dementia worldwide (Andrieu et al., 2015; Ballard et al., 2011). It was estimated that more than 47 million people suffered from dementia in 2015, a number that is expected to triple by 2050 (Prince et al., 2013; WHO, 2015). The cost AD represents for the individual, the family and society, in a rapidly aging population (WHO, 2015), puts great pressure in the need to better understand the disease and to find an effective cure or remediation, which has not been achieved to date (Andrieu et al., 2015; Ballard et al., 2011).

The main symptoms of $\mathrm{AD}$ patients are early memory loss and marked cognitive impairment (Ballard et al., 2011; Roberson and Mucke, 2006). Patients begin by presenting mild cognitive impairment $(\mathrm{MCI})$, which consists on a slight deficit in working and long-term memory and a moderate deficit in short-term and episodic memory. The appearance of $\mathrm{MCI}$ is viewed as a sign of $\mathrm{AD}$ initiation, that usually precedes the marked and irreversible mood alterations and loss of episodic memory function, observed later on, as the disease progresses and reaches a severe form (Albert, 1996; Perry and Hodges, 1999). The new diagnostic criteria and guidelines refer to three phases of disease progression over time, namely preclinical $A D, M C I$ due to $A D$ and dementia due to $A D$, and take into account, not only the important contribution of the clinical signs, but also of the changes in a panel of blood and CSF biomarkers, and of neuroimaging tests, which may add to increase the early diagnostic accuracy of the disease as they become validated (Albert et al., 2011; McKhann et al., 2011; Sperling et al., 2011). However, despite the new clinical guidelines, up to now, the post-mortem analysis of the brain is still required for the definitive diagnosis of AD (Ballard et al., 2011; Castellani et al., 2008). The two main pathological hallmarks of $A D$ are the extracellular deposition of amyloid beta $(A \beta)$ peptides in the form of senile plaques, and the formation of intracellular neurofibrillary tangles that result from the aggregation of hyperphosphorylated TAU (hpTAU) protein (Montine et al., 2012; Querfurth and LaFerla, 2010). However, according to the new guidelines, other neuropathological changes, such as the presence of Lewy body and TAR DNA binding protein-43 inclusions, vascular brain injury and hippocampal sclerosis, have been included in the post-mortem analysis of the AD brain due to commonly coexisting comorbidities (Montine et al., 2012).

In addition to the more common late-onset and sporadic form, there is also the early-onset and familial form of $\mathrm{AD}$, which is associated with dominant inherited mutations on the genes encoding for amyloid precursor protein (APP) and/or for presenilins 1 and 2 (PS1 and 2) (Goate et al., 1991; Levy-Lahad et al., 1995; Schellenberg et al., 1992). However, familial AD, which is usually diagnosed in midlife, explains only $5 \%$ of all the AD cases (Ballard et al., 2011). Age is the principal risk factor for sporadic AD, but increased risk for this form has also been attributed to diverse genetic abnormalities (Ballard et al., 2011; Naj et al., 2011), among which, is the diploidy for apolipoprotein $\mathrm{E}$ (APO-E) $\varepsilon 4$ alleles, which is one of the major genetic risk factors (Corder et al., 1993; Roberson and Mucke, 2006), promoting both an early onset of $A \beta$ aggregation and a defective $A \beta$ clearance out of the brain (Keene et al., 2011; Zlokovic, 2013).

In the past decades, some light has been shed onto the neuropathophysiological mechanisms of AD. However, the best candidate molecules/drugs, shown to produce only modest effects on the cognitive decline in $\mathrm{AD}$, are memantine and cholinesterase inhibitors (Andrieu et al., 2015; Ballard et al., 2011). In addition, although reducing the amyloid burden in the brain, $A \beta$-directed vaccination strategies were proven to have serious secondary effects and to be ineffective in reverting the behavioral deficits in AD patients (Andrieu et al., 2015; Holmes et al., 2008). On the other hand, there is an urgent need to detect AD as early as possible, since it is widely accepted that brain pathology, neuroinflammation, neuronal and synaptic loss, precede the initial signs of cognitive alterations in mild AD by at least $10-15$ years (Ballard et al., 2011; Bateman et al., 2012; Perrin et al., 2009). As an attempt to have a readout of early neural dysfunction, imaging techniques have been developed to better detect overall changes in brain size and integrity of brain networks, neural metabolism and retention of $A \beta$ identifying tracer compounds on positron emission tomography imaging (Damoiseaux et al., 2006; Engler et al., 2006; Fagan et al., 2006; Klunk et al., 2004). Moreover, the measurement of $A \beta$ and TAU (and hpTAU) in fluids, like the cerebrospinal fluid (CSF) and the blood, are also currently used to help in the diagnosis of AD (Fagan et al., 2009, 2014; Hansson et al., 2006; Villemagne et al., 2010). But, until now, there is no specific cut-off universally recognized for the definitive prognosis of $\mathrm{AD}$. It is, therefore, urgent to validate the existing biomarkers to diagnose $\mathrm{AD}$ in its early preclinical stages (before significant brain damage occurs) and to develop new disease-modifying strategies for its treatment (Ballard et al., 2011; Sperling et al., 2011). For that, it is imperative to further understand the cellular and molecular events that underlie the aging of the organism, as a whole, and of the brain in particular, and prompt for the pathological alterations in AD.

Herein, we will describe some of the mechanisms that are implicated in the pathophysiology of $\mathrm{AD}$, with a special focus on the amyloidogenic pathway and the neurotoxic effects of increased $A \beta$ formation and accumulation in the brain. Despite the reported association between increased levels of hpTAU and overt TAU pathology in the brain and the changes in the neuroinflammatory response (Faden and Loane, 2015; Metcalfe and Figueiredo-Pereira, 2010; Wes et al., 2014), in this review we will give special attention to the advances that have been made towards describing the mechanisms linking the pathological cerebral amyloidosis observed in $\mathrm{AD}$ and the alterations in the neuroinflammatory response (at the brain parenchyma and at the brain barriers) and on the peripheral immune system.

\section{The pathophysiology of AD}

Like many other neurodegenerative disorders, the most prominent histopathological feature of $\mathrm{AD}$ is the formation and accumulation of abnormally folded proteins. In the case of $A D$, there is an increased formation of intracellular neurofibrillary tangles and extracellular amyloid plaques in the brain (Haass and Selkoe, 2007; Querfurth and LaFerla, 2010). One of the most accepted theories for senile plaque formation is the amyloid cascade hypothesis (Benilova et al., 2012; Hardy and Selkoe, 2002; Roberson and Mucke, 2006), which was initially fostered by the presence of congophilic $A \beta$-enriched plaques in the brains of AD patients (Hardy and Higgins, 1992). Later on, the discovery of mutations in the genes encoding for APP, PS1 and/or PS2, in familial cases of AD, strongly corroborated the post-mortem brain pathological findings (Goate et al., 1991; Levy-Lahad et al., 1995; Schellenberg et al., 1992). Importantly, it was shown that transgenic mice overex- 
pressing at least one of the human mutated genes also presented the characteristic brain amyloid pathology of AD patients (Hsiao et al., 1996; Webster et al., 2014). Based on these observations, along the years, data from different groups helped to dissect both the role of APP in the brain and the cascade of molecular events that drive and favor the amyloidogenic proteolytic cleavage of APP. The non-amyloidogenic or the amyloidogenic cleavage of APP is triggered by the initial action of $\alpha$ - or $\beta$-secretase, respectively (Haass and Selkoe, 2007; Querfurth and LaFerla, 2010). In the amyloidogenic process, the $\gamma$-secretase complex, which is constituted by PS1, PS2 and other proteins (Edbauer et al., 2003), comes into play by acting on the sub-products of $\beta$-secretase (Gu et al., 2001; Haass and Selkoe, 2007; Wolfe et al., 1999). The $\gamma$-secretase complex can act on three different cleavage sites, originating $A \beta_{1-38}$, $A \beta_{1-40}$ and $A \beta_{1-42}$ (Gu et al., 2001), which is critical for the subsequent degree of aggregation of $A \beta$ peptides, with $A \beta_{1-42}$ displaying the higher propensity for aggregation (Suzuki et al., 1994). Noticeably, increasing evidence point to the amyloidogenic processing of APP and the oligomerization of A $\beta$ peptides in the brain as early pathogenic events, that may precede and aggravate TAU-associated brain pathology (Cras et al., 1991; Gotz et al., 2001; Lewis et al., 2001). Moreover, it is believed that the mechanisms involved in the clearance of $A \beta$ from the brain, namely through the interstitial fluid (ISF) and the CSF, are impaired not only in cases of familial AD, but also of sporadic $\mathrm{AD}$ (where there are no apparent differences in the rate of $A \beta$ formation in the brain), favoring the accumulation of these toxic peptides in the brain (Hong et al., 2011; Iliff et al., 2012; Mawuenyega et al., 2010). Although being one of the main triggering events for neurodegeneration in $\mathrm{AD}$, amyloidogenesis is accompanied by changes in other processes, namely in the brain inflammatory profile (Lucin and Wyss-Coray, 2009; Schwartz et al., 2013; Wyss-Coray, 2006). Inflammation is reported to occur early in the disease and to modulate both brain pathology and behavior, however much remains to be known about the effects of specific cellular and molecular components of the inflammatory profile in $\mathrm{AD}$. In the next section, insights on the role of different modulators of neuroinflammation in aging and in AD will be provided, and how these are considered to be relevant not only for the initiation and progression of amyloid pathology, but most of all for the appearance of cognitive deficits.

\section{Neuroinflammation in aging and in AD}

Inflammation is defined as a complex sequence of events induced by the irritation, injury and/or infection of a given tissue, that may eventually develop into a cleansing response by the components of the innate immune system and even trigger an adaptive immune response specific for the damaging agent (Owen et al., 2013). Neuroinflammation is usually present whenever an insult is imposed to the nervous tissue and is a common feature of different neurodegenerative disorders. In the last two decades, the role of neuroinflammation in aging and in $\mathrm{AD}$ has been largely scrutinized. Much has been discovered regarding the cellular and molecular players at the level of the brain parenchyma, but also at the level of the barriers of the brain and at the periphery, namely in circulation and in organs with a strong immune-related function (Baruch and Schwartz, 2013; Gabuzda and Yankner, 2013; Ransohoff, 2009, 2011; Schwartz and Baruch, 2014a; Wyss-Coray, 2006). Recent data points to changes in the degree of steady-state inflammation throughout aging, both in the CNS and in the periphery, and on its impact to CNS homeostasis and to age-associated behavioral alterations (Villeda et al., 2011; Zhang et al., 2013). As for the precise involvement of neuroinflammation in $A D$ and in other aging-related neurodegenerative disorders, it is still not clear whether inflammation is a simple bystander, a consequence or a cause of neurodegeneration (Wyss-Coray, 2006).

\subsection{The inflammatory response at the barriers of the brain in aging and in $A D$}

Under physiological conditions, the peripheral milieu is physically separated from the brain parenchyma by well-defined cellular structures that compose the barriers of the brain. In addition to their function as physical barriers, these complex structures also play a central role in the maintenance of CNS homeostasis and in the communication with other systems outside of the CNS (Marques et al., 2013; Stolp et al., 2013). Recent findings propose that alterations in the inflammatory profile in aging and in AD underline the progressive loss of essential properties at the barriers of the brain and may precipitate brain dysfunction and pathology (Baruch and Schwartz, 2013; Stolp et al., 2013; Zlokovic, 2008). Next, we will discuss some important aspects of the inflammatory response at the blood-brain barrier (BBB) and at the blood-CSF barrier (BCSFB) in aging and in AD.

\subsubsection{The inflammatory response at the $B B B$}

Most studies on the communication between the periphery and the CNS, in particular those addressing neurodegenerative disorders, focus on the BBB (Zlokovic, 2008). The BBB is formed by a monolayer of endothelial cells bound together by tight junctions (Brightman and Reese, 1969). The endothelial cells of the BBB are wrapped by the acellular basement membrane and surrounded by pericytes and astrocytic endfeets (Zlokovic, 2008). These, together with the branches of circulating surveying microglia and nearby neuronal dendritic and axonal processes, form the neurovascular unit (Zlokovic, 2008), which allows the rapid and plastic responses of the brain to alterations in the blood composition and in cerebral blood flow (Begley and Brightman, 2003). Consequently, changes in the neural-vascular communication, which are often associated with neuropathological conditions, may lead to rapid and irreversible neuronal damage (Girouard and Iadecola, 2006; Zlokovic, 2008). The mechanisms that regulate the crosstalk between the different types of cells that compose the neurovascular unit, at the BBB, have been well studied in aging and in $A D$. In fact, there is an increased accumulation and deposition of $A \beta$ in the neurovascular unit, which often culminates in cerebral amyloid angiopathy, highly prevalent in the brains of AD patients (Greenberg et al., 2004; Zlokovic, 2008). It is thought that cerebral amyloid angiopathy results from a combined effect of both an increased influx of $A \beta$ into the brain parenchyma, mediated mainly by increased expression of receptor for advanced glycation end products (RAGE) by the endothelial cells of the BBB (Deane et al., 2003), and a decreased efflux of $A \beta$ into the blood, which is largely influenced by the decreased levels of low density lipoprotein receptor-related protein-1 (LRP1) and p-glycoprotein (Pgp) (Erickson et al., 2012a; Hartz et al., 2016; Shibata et al., 2000). Decreased expression of LRP1, by endothelial cells and by pericytes, strongly influences the APO-E-dependent and -independent removal of soluble $A \beta$ from the brain parenchyma (Bell et al., 2012; Deane et al., 2008, 2004; Liu et al., 2007). Additionally, the ablation of pericytes, which are actively involved in the maintenance of the cytoarchitecture, integrity and overall function of the BBB (Armulik et al., 2010), was shown to greatly impact on the progression of vascular damage and $A \beta$ pathology in transgenic mouse models of $A D$ (Sagare et al., 2013).

Concerning the inflammatory response, different mediators were shown to modulate the cells of the $\mathrm{BBB}$ in $\mathrm{AD}$. A specific feature of the $B B B$ endothelial cells that is perturbed by increased levels of inflammation is the exchange of $A \beta$ between the brain and the blood (Banks, 2015). In a mouse model of intracerebroventricular 


\section{Physiological conditions}

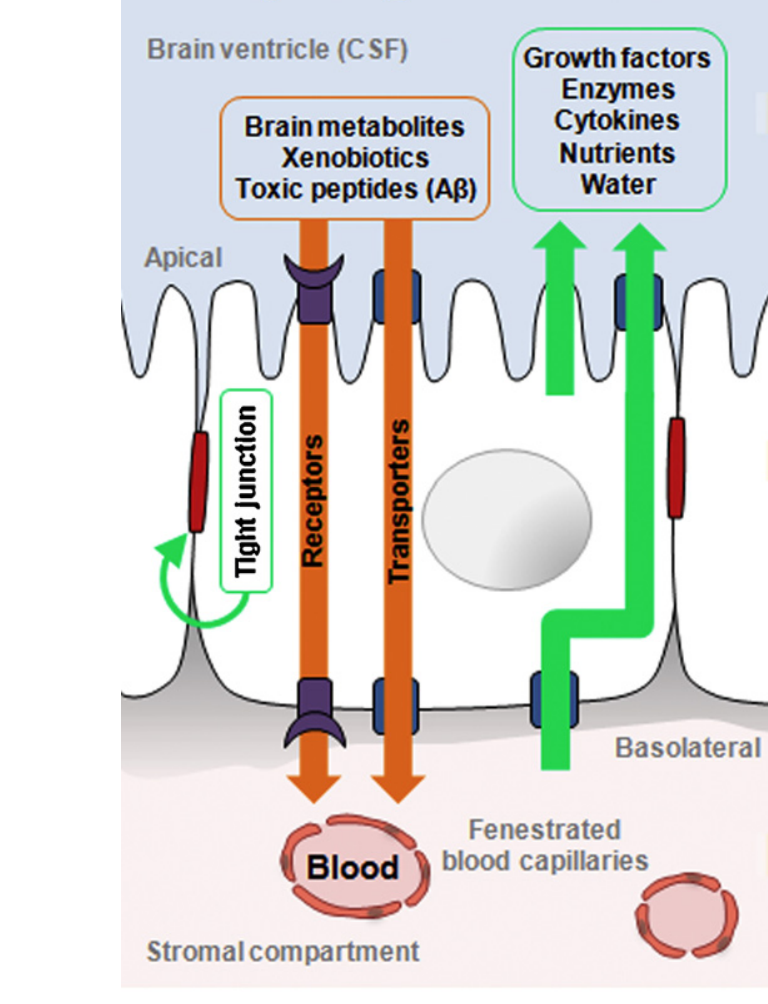

\section{Response to inflammatory stimuli}

I

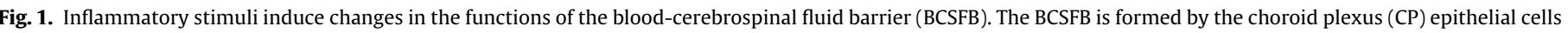

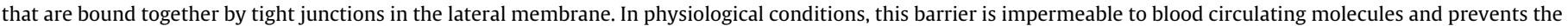

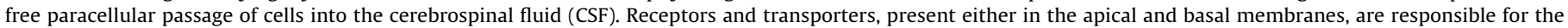

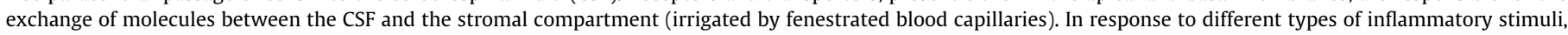

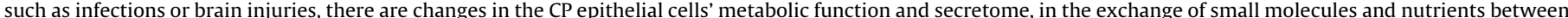

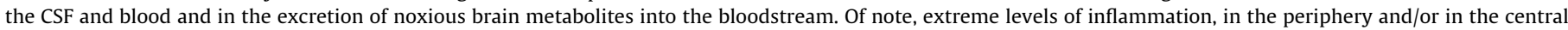

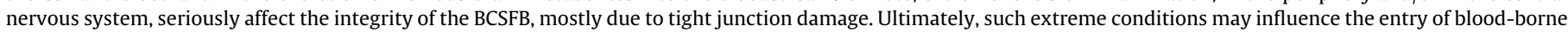
proteins and leukocyte migration/extravasation (such as macrophages and T cells) into the CSF, which can seriously affect brain homeostasis and function.

injection of $A \beta$ the increased level of systemic inflammation was shown to promote brain $A \beta$ overload through decreased expression of both LRP1 and Pgp at the level of the BBB. Curiously, this effect was counterbalanced by the systemic administration of the antioxidant $\mathrm{N}$-acetylcysteine, which decreased the levels of interferon (IFN)- $\gamma$, interleukin (IL)-10, chemokine (C-C motif) ligand 2 (CCL2), CCL4, and CCL5 in the blood and restored the values of $A \beta$ efflux into the circulation (Erickson et al., 2012a,b). Of note, the endothelial cells of the BBB are also actively involved in the blood-to-brain and brain-to-blood transport of cytokines and chemokines, such as tumor necrosis factor (TNF) and CCL11 (Erickson et al., 2014; Pan and Kastin, 2002). However, little is known about possible changes in these particular transport mechanisms, which might play a crucial role in the early neuropathological events in $A D$ (Banks, 2015). On the other hand, increased expression of RAGE was shown to induce neurovascular inflammation by promoting an increased production of TNF, IL- 6 and heme oxygenase- 1 by neural cells in the vicinity of the BBB (Deane et al., 2003). Moreover, upon binding to $A \beta$, RAGE has been shown to promote in vitro $\mathrm{T}$ cell transendothelial migration (a critical neuroimmune mechanism in AD that will be addressed in more detail in section 4), by a mechanism that involves the induction of nuclear factor$\kappa \mathrm{B}(\mathrm{NF}-\kappa \mathrm{B})$-dependent inflammatory gene expression (Bierhaus et al., 1997; Yan et al., 1996), particularly overexpression of the gene encoding for chemokine ( $\mathrm{C}-\mathrm{C}$ motif) receptor 5 (CCR5) (Li et al., 2009). The altered function of pericytes in models of AD (Sengillo et al., 2013; Tigges et al., 2013), together with their ability to respond to pro-inflammatory cytokines, like IFN- $\gamma$, TNF and IL-
$1 \beta$, and to produce chemokines, namely chemokine ( $\mathrm{C}-\mathrm{X}-\mathrm{C}$ motif) ligand 10 (CXCL10) and CCL2 (Jansson et al., 2014; Tigges et al., 2013), denote the importance of these cells in the neuroinflammatory response in $\mathrm{AD}$. A particular study shows that the expression of human APO-E\&4 in the mouse brain resulted in an age-dependent progressive $\mathrm{BBB}$ breakdown, by activating the pro-inflammatory cyclophilin A and the downstream NF-кB-dependent matrix metalloproteinase 9 pathway in capillary pericytes (Bell et al., 2012). Curiously, this pro-inflammatory pathway, which preceded neuronal dysfunction, was suppressed upon the expression of human $\mathrm{APO}-\mathrm{E} \varepsilon 2$ or $-\mathrm{E} \varepsilon 3$ that, in contrast with $\mathrm{APO}-\mathrm{E} \varepsilon 4$, also display a higher affinity for LRP1 and, therefore, are more efficient in promoting $A \beta$ excretion through the BBB (Bell et al., 2012; Deane et al., 2008; Keene et al., 2011). Moreover, the increased BBB permeability that was observed in the brains of $\mathrm{AD}$ transgenic mice devoid of pericytes (Sagare et al., 2013), points to the importance of these cells in maintaining a well-adjusted exchange of inflammatory molecules and/or cells between the blood and the brain in AD (Hurtado-Alvarado et al., 2014; Keene et al., 2011), a feature that should be further investigated. Another molecule that is able to modulate the inflammatory profile in $\mathrm{AD}$ is transforming growth factor- $\beta$ (TGF- $\beta$ ), which was shown to be overproduced by astrocytes, resulting in the decreased parenchymal $A \beta$ accumulation and plaque formation but increased cerebrovascular amyloidosis (Wyss-Coray et al., 2001). This effect of TGF- $\beta$ seems to be mediated by a decreased cross-talk between endothelial cells and T cells, resulting in decreased $T$ cell activation and reduced $A \beta$ phagocytosis by macrophages and microglia in the vicinity of the BBB 
(Weiss et al., 2011). In fact, brain perivascular myeloid cells play a key role in the management of brain pathology in AD (MeyerLuehmann and Prinz, 2015). Moreover, changes at the level of BBB may critically impact on monocyte recruitment and $A \beta$ removal from the luminal walls of $A \beta$-positive veins, which was shown to directly impact on the progression of pathology in an AD transgenic mouse model (Michaud et al., 2013a). Still, we are far from understanding all the details regarding the effects of increased levels of specific inflammatory mediators on the different cells that compose the neurovascular unit and on the relevance of this effect for $\mathrm{AD}$ initiation and progression.

\subsubsection{The inflammatory response at the BCSFB}

Recent studies have highlighted the alterations observed at the level of the choroid plexus (CP), which forms the BCSFB, and their impact on brain function in aging and in AD (Baruch et al., 2014, 2013, 2015; Mesquita et al., 2014, 2015). The CP is formed by a monolayer of epithelial cells bound together by tight junctions, which are formed by claudins and occludins present in the lateral side of the apical membrane (Ek et al., 2003; Wolburg et al., 2001). The apical membrane of CP epithelial cells contains numerous microvilli, while the basal membrane faces the inner stroma compartment, which is highly irrigated by sinusoidal and fenestrated capillaries (Johansson et al., 2008; Wolburg and Paulus, 2010) (Fig. 1). In adulthood, and in healthy conditions, the $\mathrm{CP}$ forms a selective barrier that restricts the paracellular passage of molecules and cells, like blood circulating immune cells, from the stromal compartment into the CSF and into the brain parenchyma (Baruch and Schwartz, 2013; Engelhardt et al., 2001; Hasegawa-Ishii et al., 2013). In fact, under physiological conditions, the monocytes/macrophages and $\mathrm{T}$ cells that inhabit the $\mathrm{CP}$ play an essential role in the immune surveillance of the brain and contribute to CNS homeostasis and repair, by secreting and maintaining the levels of important trophic factors and cytokines (Baruch and Schwartz, 2013; Schwartz and Baruch, 2014b) (Fig. 1). Concerning the recruitment and entry of immune cells through the $\mathrm{CP}$, the current view states that it is mediated by the expression of intercellular adhesion molecule 1 (ICAM-1), vascular cell adhesion molecule 1 and P-selectin, which are essential for the process of leukocyte adhesion and extravasation (Engelhardt et al., 2001; Kunis et al., 2013; Shechter et al., 2013).

Interestingly, recent studies point for a central role of the $\mathrm{CP}$ in the neuroinflammatory response both in aging and in AD (Baruch et al., 2014; Baruch et al., 2015; Mesquita et al., 2015). Particularly in $A D$, the BCSFB suffers alterations not only due to increased levels of toxic $A \beta$ (Chalbot et al., 2011; Vargas et al., 2010), but also promoted by different blood-born inflammatory molecules and immune cells (Baruch et al., 2015; Schwartz and Baruch, 2014b). Altogether, this altered inflammatory profile at the BCSFB impacts on the CSF-ISF nexus and, consequently, on brain homeostasis and on neurodegeneration (Baruch and Schwartz, 2013; Chalbot et al., 2011; Iliff et al., 2012). Moreover, aging-associated alterations in the secretion of inflammatory molecules by the cells that compose the $\mathrm{CP}$ tissue, either by the epithelial or the stromal cells, is viewed as a critical turning point for deficits in brain cell function and plasticity, and were shown to affect processes like glial activation, neurogenesis and cell survival (Baruch et al., 2014, 2013; Kunis et al., 2013; Villeda et al., 2011). Regarding the inflammatory response in the context of AD-associated pathology, we recently found that the $\mathrm{CP}$ epithelial cells overexpress the gene encoding for lipocalin 2 (LCN2) upon stimulation with $A \beta$ peptides (Mesquita et al., 2014). Of interest, LCN2 is involved in the innate immune response (Devireddy et al., 2005; Flo et al., 2004) and its up-regulation is indicative of a rapid pro-inflammatory profile build-up at the $\mathrm{CP}$ (Marques et al., 2008, 2009). Additionally, despite its ability to deliver or remove iron from cells (Devireddy et al., 2005; Lee et al., 2009), LCN2 has been suggested to act in the response against oxidative stress (Roudkenar et al., 2011), in the regulation of the neuroinflammatory response and in the modulation of brain cell activation, migration and survival (Bi et al., 2013; Jang et al., 2013b; Lee et al., 2011, 2009), which are all particularly relevant functions in the context of AD. Of note, it was shown that AD patients present altered levels of LCN2 in the CSF (Naude et al., 2012), and that LCN2 is involved in the in vitro pro-inflammatory response to increased level of $A \beta$ peptides, displaying a detrimental effect on brain cell survival (Mesquita et al., 2014). Considering this new evidence, it will be important to further elucidate the role of LCN2 in the context of an in vivo model of AD.

Along with the changes in the composition of the CSF, it was recently proposed that aging leads to peripheral systemic alterations in molecules that reach the brain parenchyma and affect neurogenesis at the hippocampus and the formation of new memories in 22 months-old mice (Villeda et al., 2011, 2014). Particular interest has been given to increased levels of CCL11 as being, to a great extent, responsible for this effect (Villeda et al., 2011). It is now clear that peripheral CCL11 can cross into the brain through direct interaction with the BBB, reaching, not only the neurogenic niches, but other brain regions as well (Erickson et al., 2014). This suggests that blood-derived CCL11 may impact on different brain key processes and implicates the BBB as an important regulator of its effects (Erickson et al., 2014; Villeda et al., 2011). In addition to the effects of peripheral CCL11 on neurogenesis and cognitive function, it was recently shown that the ability of activated astrocytes to produce this chemokine is associated with increased migration of microglia, production of reactive oxygen species by these glial cells and glutamate-mediated neurotoxicity, which may suggest a role in neurodegenerative disorders (Parajuli et al., 2015). Still regarding the role of CCL11, there is evidence showing that increased levels of CCL11 in the brain may also be attributed to changes at the BCSFB (Baruch et al., 2013; Villeda et al., 2011). Of note, it was shown that aged mice, when compared to young adult mice, present an overexpression of the gene that encodes for CCL11 in the CP (Baruch et al., 2013) and, accordingly, increased CCL11 protein levels in the CSF (Villeda et al., 2011). Furthermore, the CP epithelial cells are able to produce CCL11 in response to IL-4, but not in response to IFN- $\gamma$. In fact, increased IFN- $\gamma$ was shown to be able to block the IL-4-dependent CCL11 production by CP epithelial cells (Baruch et al., 2013). In vivo, the aging-induced increase of IL-4 and decrease of IFN- $\gamma$ at the $\mathrm{CP}$ were suggested to be a consequence of alterations in the type of CNS-specific T cells recruited to the CP stroma (Baruch et al., 2013). It was also proposed that an altered inflammatory response in the CP could impact on the function of brain cells by decreasing the level of brain-derived neurotrophic factor (BDNF) produced by CP epithelial cells (Baruch et al., 2013). Concurrently with these observations, it was shown that in the aged $\mathrm{BCSFB}$, there is down-regulated expression of the gene encoding for IFN- $\gamma$ and a boosted expression of type I IFN response genes (Baruch et al., 2014). Both the aged murine and human CP presented increased levels of IFN regulatory factor 7 and IFN- $\beta$, two classical type I IFN molecules (Baruch et al., 2014). Importantly, it was suggested that the induction of type I IFN response at the CP of old mice, together with increased levels of CCL11, was mediated by increased levels of unknown brain-derived factors in the CSF, and not by circulating factors present in the blood. It was also proposed that this CNS-driven boost of the type I IFN response at the $\mathrm{CP}$, together with a down-regulated type II IFN response, could contribute to the increased glial activation in brain regions that modulate memory and cognitive behaviors in old mice (Baruch et al., 2014; Villeda et al., 2011, 2014). In fact, the exacerbated gliosis and neuroinflammation, decreased hippocampal neurogenesis and spatial memory deficits observed in aged mice were reverted via the intracerebroventricular administration of neutralizing anti- 


\section{Phenotypic polarization of astrocytes and microglia}

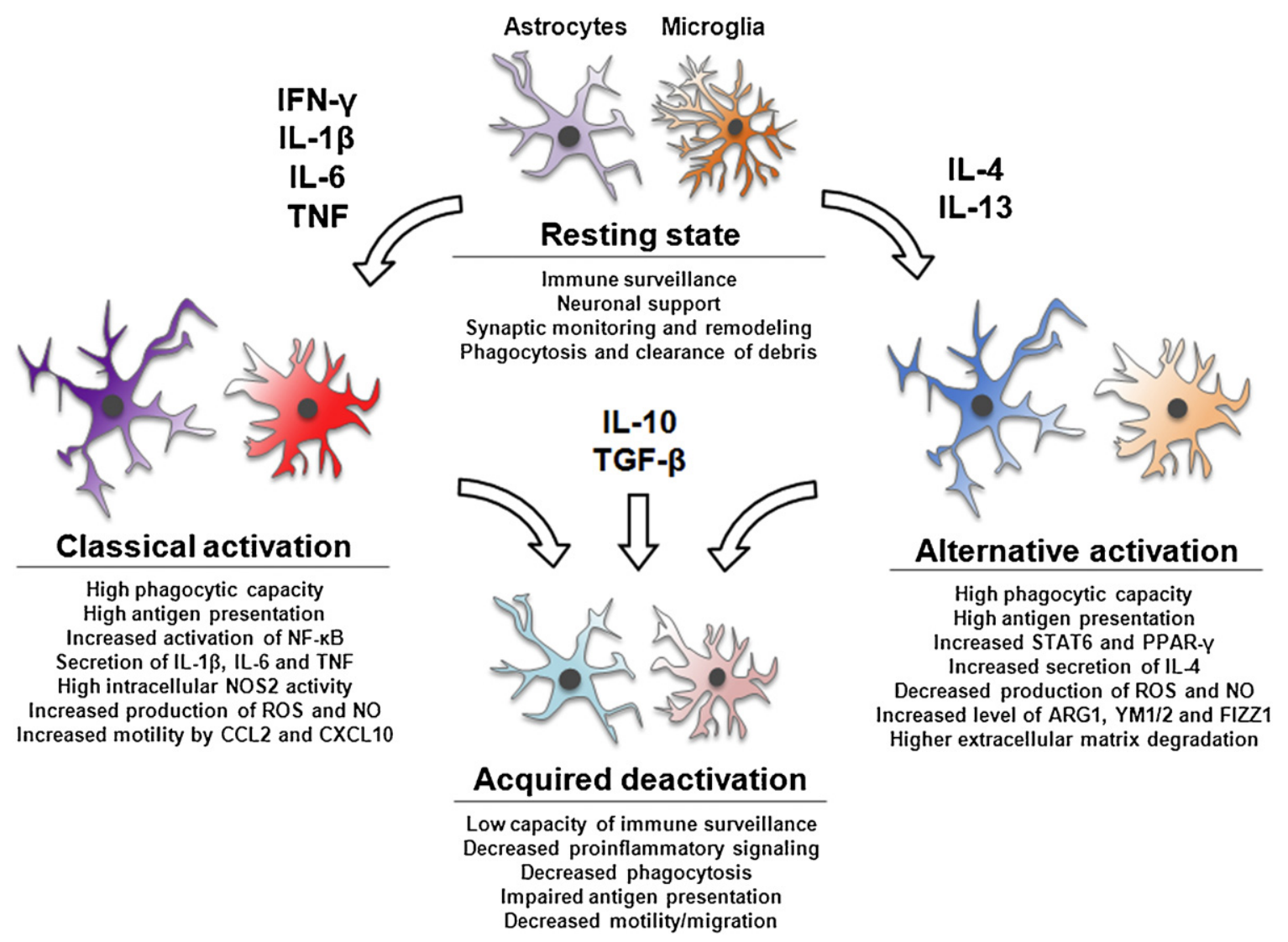

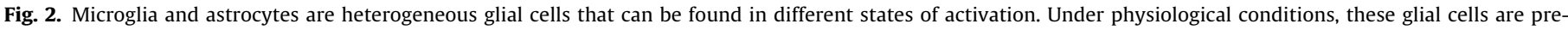

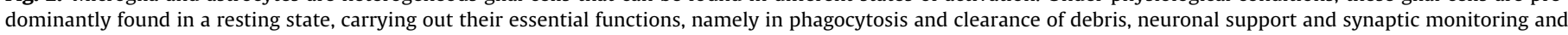

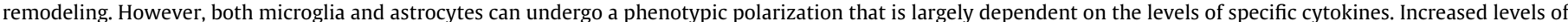

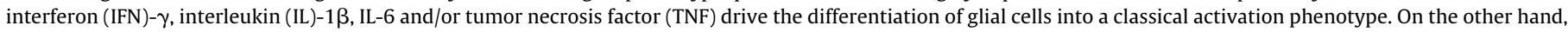

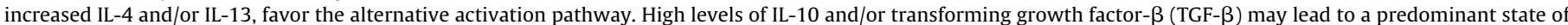

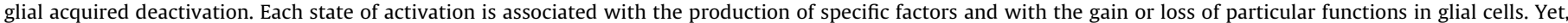

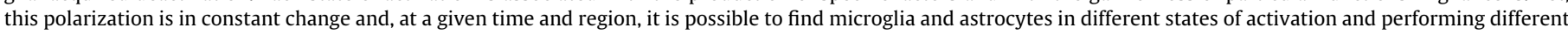
functions.

bodies to the receptor for type I IFNs (Baruch et al., 2014). Along with the previous study, we have recently discovered that type I IFN response genes, such as the genes encoding for toll-like receptor 9 (TLR9) and for IFN- $\alpha$ receptor 1 , are overexpressed in the CP and in the dorsal hippocampus of an AD transgenic mouse model at 3 months, when compared to wild-type age-matched controls (Mesquita et al., 2015). Moreover, this early overexpression of the type I IFN response genes was followed by a marked decrease in the expression of the gene encoding for IFN- $\gamma$, the major type II IFN response cytokine, at later ages (Mesquita et al., 2015). Whether these alterations in type I and II IFN responses at the CP and brain parenchyma are somehow modulating the behavioral impairments observed in AD justify further investigation.

\subsection{Brain parenchymal cells as mediators of neuroinflammation}

The idea of an immuno-privileged brain started to evolve upon the discovery of activated antigen-presenting immune cells, expressing the major histocompatibility complex type II glycoprotein, within the CNS of patients with different neurodegenerative disorders, namely AD (McGeer et al., 1988; Medawar, 1948; Rogers et al., 1988). Much has been discovered since then and the notion of an immuno-privileged brain has been progressively changing in accordance with the advances in the field. Nowadays, it is widely accepted that even the cells that constitute the brain parenchyma are actively involved in the neuroinflammatory processes and are able to directly or indirectly influence the immunological response in aging and in AD (Griffin, 2013; Wyss-Coray, 2006). As a matter of fact, the recent discovery of meningeal lymphatic vessels opened a new window for neuroimmune interactions within the CNS (Louveau et al., 2015a,b). In the next sections, we will provide an overview on the contribution of microglia, astrocytes, neurons and oligodendrocytes to the neuroinflammatory response.

\subsubsection{Microglia}

Microglial cells are considered the macrophages of the brain, due to their myeloid origin, ability to migrate within different brain regions and to phagocytose, process and present antigens (Neumann et al., 2009; Nimmerjahn et al., 2005; Ransohoff and Perry, 2009). It has been shown that, during fetal development, myeloid progenitor cells, arising from the yolk sac at early embryonic stages, invade the brain to give rise to microglia (Katsumoto et al., 2014; Rezaie and Male, 2002). It is believed that under physiological conditions, the microglial population in the brain remains immutable; however, recent studies pointed to the existence of monocyte-derived microglial progenitors that are able to proliferate and repopulate the adult brain in case of severe microglial depletion (Elmore et al., 2014; Varvel et al., 2012). Both in early 


\section{Modulators of brain parenchymal inflammation in AD}

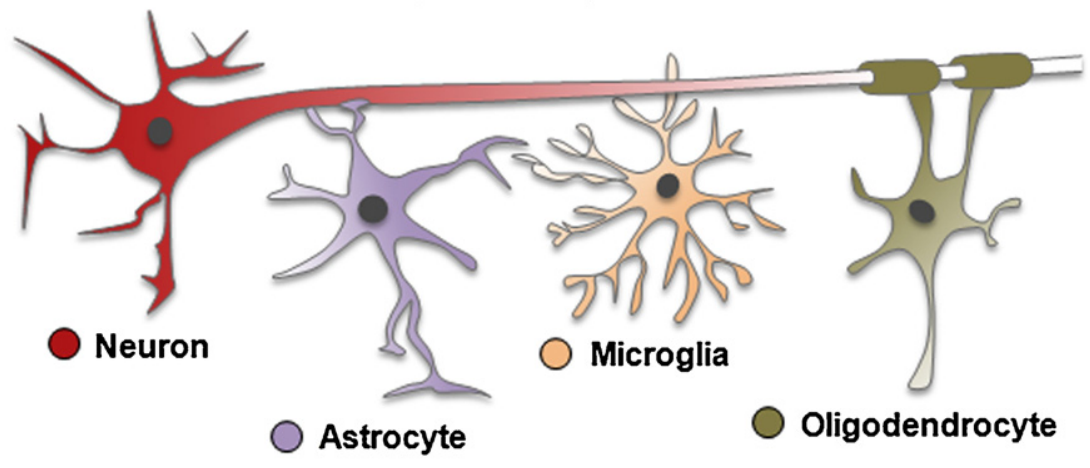

Inflammatory molecules and major cellular sources (reported in the literature)

\begin{tabular}{|c|c|c|c|c|}
\hline $\begin{array}{l}\text { IL-1 } \\
\text { IL-6 } \\
\text { IL-8 } \\
\text { IL-12 } \\
\text { IL-23 } \\
\text { TNF } \\
\text { C1q } \\
\text { C3 } \\
\text { C4 } \\
\text { CCL2 } \\
\text { CCL5 } \\
\text { M-CSF }\end{array}$ & $\begin{array}{r}000 \\
000 \\
0 \\
0 \\
0 \\
00 \\
0 \\
0 \\
0 \\
0 \\
00\end{array}$ & $\begin{array}{l}\text { TGF- } \beta \\
\text { CX3CL1 } \\
\text { CXCL1 } \\
\text { CXCL10 } \\
\text { IFN- } \alpha \\
\text { IFN- } \beta \\
\text { TLR2 } \\
\text { TLR4 } \\
\text { TLR9 } \\
\text { TREM2 } \\
\text { CR2 } \\
\text { CCR2 }\end{array}$ & $\begin{array}{ll}0 & 0 \\
0 & \\
0 & \\
0 & 0 \\
0 & \\
0 & \\
& 0 \\
0 & 0 \\
0 & 0 \\
0 & 0 \\
0 & 0 \\
0 & 0\end{array}$ & $\begin{array}{l}\text { CX3CR1 } \\
\text { CD11B } \\
\text { CD14 } \\
\text { CD22 } \\
\text { CD36 } \\
\text { CD59 } \\
\text { CD200 } \\
\text { GFAP } \\
\text { S100B } \\
\text { RAGE } \\
\text { NO } \\
\text { NOS2 }\end{array}$ \\
\hline
\end{tabular}

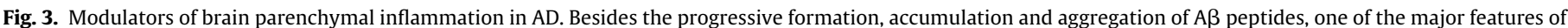

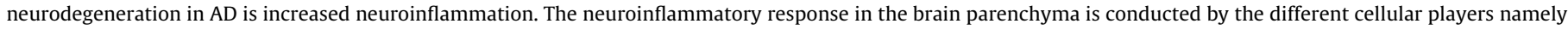

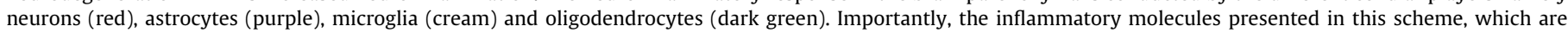

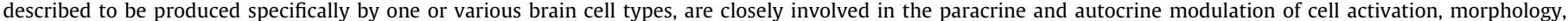

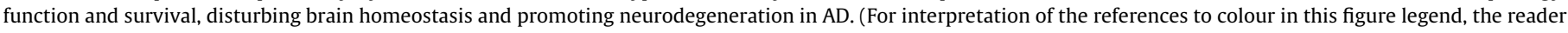
is referred to the web version of this article.).

post-natal phases and in the adult brain, microglia secrete soluble factors, like insulin-like growth factor 1 (IGF-1) and BDNF, which regulate neurogenesis, neuronal migration and survival (Parkhurst et al., 2013; Ueno et al., 2013; Walton et al., 2006). Under physiological conditions, resting microglia play a crucial role in the immune surveillance of the brain, interacting with the other brain cells and actively monitoring and remodeling impaired synapses (Nimmerjahn et al., 2005; Wake et al., 2009). Importantly, under adverse conditions, like brain tissue trauma, upon phagocytosis of noxious agents, or in response to exogenous stimuli (such as signaling by pro-inflammatory cytokines or recognition of pathogen-associated molecular patterns), microglia become activated (Cameron and Landreth, 2010; Lampron et al., 2013). However, both in the steady or the activated states, microglia are able to secrete inflammatory mediators, anti- or pro-inflammatory, that act as paracrine mediators of neural cell plasticity and survival but that may also promote the autocrine polarization into different states of activation (Cameron and Landreth, 2010; Katsumoto et al., 2014) (Fig. 2). The classical activation cytokines, including IFN- $\gamma$, IL-1 $\beta$, IL- 6 and TNF, induce the polarization of microglia into a pro-inflammatory surveying phenotype, as opposed to the alternative activation pathway, which is favored by increased levels of IL- 4 and IL-13. On the other hand, the anti-inflammatory cytokines IL-10 and TGF- $\beta$ promote the acquired deactivation of microglia (Cameron and Landreth, 2010; Katsumoto et al., 2014) (Fig. 2). Importantly, the phenotypes acquired by microglia are mutable and may vary according to the type of stimuli, the evolu- tion of the inflammatory response and also with aging (Katsumoto et al., 2014; Lucin and Wyss-Coray, 2009; Ransohoff and Perry, 2009). Of note, it has been shown that, in the tissue-rebuilding phase that follows a pro-inflammatory response, microglia undergo a transition from a predominantly classical activated phenotype into a mixed combination of activation phenotypes; this has been associated with an alteration in microglial function and increased brain pathology in AD transgenic mouse models (Baron et al., 2014; Cameron and Landreth, 2010; Weekman et al., 2014; WyssCoray, 2006). Importantly, whether isolated from the brains of different mouse models of $A D$ or from the brain of wild-type mice and stimulated with $A \beta$ peptides, microglial cells are able to secrete cytokines (e.g., IL-1 $\beta$, IL-6, IL-12, IL-23 and TNF) (Bhaskar et al., 2014; Combs et al., 2001; Lue et al., 2001; Vom Berg et al., 2012), chemokines [e.g., CCL2 and IL-8] (El Khoury et al., 2007; El Khoury et al., 2003; Walker et al., 2001), growth factors [e.g., macrophage-colony stimulating factor (M-CSF)] (Lue et al., 2001) and complement molecules (e.g., C1q, C3, and C4) (Walker et al., 1995) (Fig. 3). Besides these secreted factors, microglia also express numerous surface receptors that are involved in the modulation of their activation, migration and phagocytosis capacity in response to increased $A \beta$, namely: receptors for Fc, cytokines and chemokines (e.g., CCR2), scavenger receptors [e.g., cluster of differentiation 36 (CD36) and RAGE], complement receptors (e.g., CR3/CD11B), TLRs and the co-receptor CD14 (Bard et al., 2000; Chakrabarty et al., 2010a,b, 2011; Chen et al., 2007; El Khoury et al., 2007; El Khoury et al., 2003; Ransohoff, 2009; Reed-Geaghan et al., 2009; Scholtzova 
et al., 2009) (Fig. 3). Noticeably, the ablation of the type 1 receptor for the chemokine C-X3-C motif ligand 1 (CX3CL1), CX3CR1, seems to seriously impact on the pathophysiology of AD (Fig. 3), leading to an increased phagocytosis of $A \beta$ by microglia and to a decreased microglial-induced neuronal death in vivo (Fuhrmann et al., 2010; Liu et al., 2010). Moreover, it was recently shown that the ablation of prostaglandin E2 signaling, specifically in microglia from the brain of an $A D$ transgenic mouse model, restored microglial chemotaxis and $A \beta$ clearance and suppressed the toxicity of the exacerbated pro-inflammatory response and microglial activation (Johansson et al., 2015). Microglial cells may also present different activation phenotypes according to the type of APO-E isoform that is expressed. Microglia isolated from the brain of mice expressing APO-E $\varepsilon 4$ present an enhanced pro-inflammatory activation phenotype and are more neurotoxic, secreting higher levels of TNF and IL-6, when compared to microglia expressing APO-E 22 or Eع3 (Maezawa et al., 2006; Vitek et al., 2009). Furthermore, it was demonstrated that IL-10, a relevant anti-inflammatory cytokine, and IL-4, when overexpressed in the brains of an AD transgenic mouse model, impair the activation of microglial cells, boost the formation of amyloid plaques and critically impact on synaptic function, learning and memory (Chakrabarty et al., 2015, 2012). In accordance, an opposite effect was observed in the brain of an $\mathrm{AD}$ transgenic mouse model unable to produce IL-10 (GuillotSestier et al., 2015). Nevertheless, additional studies are needed to fully understand the effects of anti-inflammatory cytokines on microglial function in AD. Altogether, the available information indicates that the microglial response is complex, particularly the regulation of microglial activation and its impact on the removal of dead cells and of molecular aggregates, which are vital processes for a healthy CNS (Cameron and Landreth, 2010; Katsumoto et al., 2014). Whether microglia activation, when uncontrolled, drives neurodegeneration and leads to cognitive decline in $\mathrm{AD}$, is still a subject of debate.

\subsubsection{Astrocytes}

Astrocytes are the most abundant cells in the CNS, and actively modulate the structure and function of the brain during development and in adulthood, both in health and in disease (Sofroniew and Vinters, 2010; Ullian et al., 2001). Noticeably, in the human brain grey matter, the processes of a single astrocyte are able to reach more than $10^{5}$ synapses (Halassa et al., 2007). Astrocytes are well known for their role in the trophic and metabolic support to neurons, neuronal signal transmission and synaptic formation and plasticity (Halassa and Haydon, 2010; Henneberger et al., 2010; Oberheim et al., 2008; Perea et al., 2009). In addition, these glial cells are also active players in the inflammatory response, particularly in the context of aging and AD (Avila-Munoz and Arias, 2014; Medeiros and LaFerla, 2013). Astrocytes are a highly heterogeneous cellular population from which at least two distinct types are particularly relevant when addressing AD: (i) those that compose the neurovascular unit, at the BBB, and (ii) those that inhabit the brain parenchyma and are often found in the vicinity of AD senile plaques (Avila-Munoz and Arias, 2014; Medeiros and LaFerla, 2013; Sofroniew and Vinters, 2010). At the BBB, astrocytes are closely involved in the organization of the neurovascular unit and secrete vasoactive molecules, like prostaglandins and nitric oxide (NO), that affect the cerebral blood flow (Gordon et al., 2007; Iadecola and Nedergaard, 2007; Schummers et al., 2008; Voskuhl et al., 2009). However, the contribution of astrocytes to vascular dysfunction and reduced microcirculation, which occur early in the AD brain (Iadecola, 2004; Meyer et al., 2008), is still poorly understood.

In general, astrocytes are highly plastic cells that depend on intracellular calcium oscillations to become excited, and on intercellular calcium signaling for astrocyte-astrocyte and astrocyte- neuron communication (Cornell-Bell et al., 1990; Shigetomi et al., 2008; Shigetomi et al., 2010). This feature is especially relevant since parenchymal astrocytes display increased cytosolic calcium, both in response to high levels of soluble $A \beta$ peptides or in the presence of $A \beta$ plaques, which was shown to affect both the survival of astrocytes and of surrounding neurons (Abramov et al., 2004; Oseki et al., 2014). Importantly, it is accepted that the activation of astrocytes is associated with the overexpression of glial fibrillary acidic protein (GFAP), a process often referred to as astrogliosis. However, GFAP is not a marker for all steady-state astrocytes and is sometimes not immunohistochemically detectable in astrocytes of the healthy CNS tissue (Pekny et al., 1995; Pekny and Pekna, 2004; Sofroniew and Vinters, 2010; Voskuhl et al., 2009). Despite the lack of knowledge concerning the functional meaning of increased levels of GFAP in astrocytes, the overexpression of GFAP in the context of $\mathrm{AD}$, both in vitro, in response to $\mathrm{A} \beta$ peptides, and in vivo, in the $\mathrm{AD}$ brain, is accepted as an indicator of neuroinflammation (Abramov et al., 2004; Oberheim et al., 2008; Pekny et al., 1995). Recent data highlight the importance of studying the expression of different GFAP isoforms to better understand the pathogenesis of AD (Kamphuis et al., 2014). In the brain of aged transgenic mouse models of $\mathrm{AD}$ and in the brain of human $\mathrm{AD}$ patients, astrocytes were shown to acquire a pro-inflammatory activated phenotype that is associated with a reduced expression of genes encoding for proteins involved in neuronal support, such as the glutamate aspartate transporter, the potassium transporter Kir 4.1, glutamine synthetase and the water channel aquaporin 4 (Orre et al., 2014). Importantly, similar to microglia, several inflammatory molecules were shown to mediate astrocytic activation in the AD brain, leading to the accumulation of astrocytes into the vicinity of large $A \beta$ aggregates and plaques, and to the formation of glial scar-like structures, in which these cells provide a barrier between healthy tissue and areas of injury (Sofroniew and Vinters, 2010). The cytokines IFN- $\gamma$, IL-1 $\beta$, IL6 and TNF are described as mediators of the classical pro-inflammatory activation of astrocytes (Carrero et al., 2012; Chakrabarty et al., 2010a,b, 2011; Ghosh et al., 2013; Hsiao et al., 2007; Xu et al., 2010) (Fig. 2). The mechanism of astrocytic activation by pro-inflammatory cytokines, such as TNF, is in part mediated by increased intracellular calcium and astrocyte depolarization (Hsiao et al., 2007; Koller et al., 1996). Surprisingly, it was shown that certain combinations of pro-inflammatory cytokines, like IFN- $\gamma$ together with IL- $1 \beta$ or TNF, were able to trigger $A \beta$ production by astrocytes, by boosting $\beta$-secretase activity (Blasko et al., 2000). Due to their ability to express both APP and presenilins, both glial and neuronal cells are able to contribute to the extracellular accumulation of $A \beta$ peptides in the $A D$ brain (Kamenetz et al., 2003; Veeraraghavalu et al., 2014). In fact, recent studies demonstrate that glial cells, astrocytes in particular, together with excitatory neurons (widely considered as the primary source of the $A \beta$ peptides), are responsible for the early extracellular $A \beta$ accumulation in the brain of $\mathrm{AD}$ transgenic mice, which suggests that the proinflammatory glial activation observed in the AD brain might in fact directly contribute to increased amyloidosis (Furman et al., 2012; Liao et al., 2016; Veeraraghavalu et al., 2014). On the other hand, it was recently suggested that increased levels of the antiinflammatory IL-10, specifically in the brain of an AD transgenic mouse model, lead to increased production of APO-E by astrocytes and increased levels of $A \beta$ plaque-associated APO-E, which seems to have a detrimental effect on $A \beta$ phagocytosis by glial cells (Chakrabarty et al., 2015). This outcome of increased levels of IL-10 seems to occur through the polarization of astrocytes and microglia into a deactivated phenotype (Cameron and Landreth, 2010; Chakrabarty et al., 2015; Guillot-Sestier et al., 2015) (Fig. 2). Curiously, facing the same pro-inflammatory stimulus in the brain, mice devoid of endogenous APO-E and expressing the APO-E\&3 isoform present a greater degree of astrocytic activation when 
compared to those expressing APO-E\&4, which is again suggests an association between an AD-related haplotype and astrocytic deactivation and/or dysfunction (Ophir et al., 2003). Furthermore, cytokines, like the anti-inflammatory TGF- $\beta$, and chemokines, such as CCL2 and CXCL10, are also involved in the activation of both microglia and astrocytes (Fig. 3), promoting chemotaxis towards sites of $A \beta$ accumulation and $A \beta$ phagocytosis and degradation (Krauthausen et al., 2015; Wyss-Coray et al., 2001, 2003). Importantly, in response to increased levels of $A \beta$, astrocytes, similarly to microglia, can contribute to the maintenance of a pro-inflammatory milieu by producing IL-1 $\beta$, IL-6, TNF, nitric oxide synthase 2 (NOS2), NO, CCL2, CXCL10 and TGF- $\beta$ (Garwood et al., 2011; White et al., 2005; Wyss-Coray et al., 2001, 2003) (Fig. 3). In fact, the effect of $\mathrm{A} \beta$ peptides on the pro-inflammatory activation of astrocytes and microglia has been shown to be achieved through the activation of particular inflammation-associated transcription factors, such as NF-кB (Akama et al., 1998; Bonaiuto et al., 1997). A persistent pro-inflammatory milieu and a chronic activation of astrocytes is associated with a loss of essential functions, namely of glutamate uptake and BBB ensheathing (Bush et al., 1999; Rothstein et al., 1996), and a gain of detrimental functions, including increased levels of calcium and the overproduction and secretion of additional neurotoxic proteins, such as S100B and LCN2 (Lee et al., 2009; Mori et al., 2010; Petzold et al., 2003). Altogether, these might aggravate the pro-inflammatory profile and overall CNS pathology in AD (Medeiros and LaFerla, 2013; Sofroniew and Vinters, 2010). Of note, as referred before, LCN2 was shown to be overproduced also by astrocytes, in vitro, in response to $A \beta$ peptides (Mesquita et al., 2014) and to be increased in the brain of AD patients (Naude et al., 2012). Moreover, it was recently shown that increased levels of LCN2 in the brain may promote, not only the autocrine regulation of astrogliosis (Lee et al., 2009) and microglial activation, favoring the glial polarization into a classical activated phenotype (Jang et al., 2013a, b), but also the death of neurons (Bi et al., 2013).

\subsubsection{Neurons}

Often observed as secondary participants in the brain inflammatory process, neurons are also able to express important molecules that modulate the course and outcomes of the inflammatory response in $\mathrm{AD}$. In particular, neurons are able to secrete $\mathrm{CD} 22$ and CD200, which are recognized by their receptors expressed by microglia and are able to down-regulate the pro-inflammatory phenotype of these glial cells (Fig. 3). The low levels of the antiinflammatory molecules CD22 and CD200 in the AD brain have been associated with the setup of chronic inflammation (Mott et al., 2004; Walker et al., 2009). Also, the deficits in neuronal function in different animal models of aging and AD are viewed as a consequence of changes in complement cascade proteins (WyssCoray, 2006; Wyss-Coray et al., 2002). An example of this is the increased proliferation of neural progenitor cells observed in the hippocampus of 16 months-old mice lacking CR2 (a receptor for C3 and IFN- $\alpha$ ), when compared to age-matched wild-type mice (Moriyama et al., 2011); on the other hand, the ablation of CD59(the major inhibitor of the formation of the membrane attack complex) was associated with increased levels of neuronal TAU hyperphosphorylation and synaptic loss in a model of AD-like tauopathy (Britschgi et al., 2012), which indicates the relevance of complement proteins in different aspects of neurodegeneration in AD (Fig. 3). Noticeably, neurons are also able to express RAGE, which contributes to increased neuroinflammation in AD by mediating the influx of $A \beta$ into neuronal cells and, consequently, by promoting NF- $\kappa \mathrm{B}$ activation and the increased production and secretion of M-CSF (Du Yan et al., 1997). In fact, increased levels of A $\beta$ peptides are able to promote neuronal overexpression of IL-6, TNF, CXCL1, CCL2, CCL5, CX3CL1 and ligands of the triggering receptor expressed on myeloid cells 2 (TREM2) (Fuhrmann et al., 2010;
Hsieh et al., 2009; Lee et al., 2014; Leow-Dyke et al., 2012; Lin et al., 2013; Roussos et al., 2014) (Fig. 3). As mentioned before, CX3CR1 is highly expressed in microglia, yet its ligand CX3CL1 is mostly produced by neurons. Importantly, the effect of CX3CR1and CX3CL1-deficiency on the reduction of the amyloid burden in an $\mathrm{AD}$ transgenic mouse model has been shown to be mostly due to the membrane-anchored version of CX3CL1 on neurons and not to the released form of the chemokine (Fuhrmann et al., 2010; Lee et al., 2014). However, CX3CL1 is involved in the activation of p38 mitogen-activated protein kinase-dependent microglial phagocytosis of A $\beta$ (Fuhrmann et al., 2010; Lee et al., 2014). Additionally, decreased levels of neuronal-derived ligands of microglial TREM2 were shown to reduce the phagocytosis of apoptotic neurons by microglia, and were correlated with increased production of TNF and NOS2, aggravating the pathogenesis in the AD brain (Hsieh et al., 2009; Roussos et al., 2014; Takahashi et al., 2005). Noticeably, it was recently reported that $A \beta$ peptides are able to induce the neuronal overexpression of genes encoding for the type I IFN cytokines, IFN- $\alpha$ and IFN- $\beta$, prior to the overexpression of other classical pro-inflammatory cytokines, and that signaling by these molecules modulates $A \beta$-induced neurotoxicity (Taylor et al., 2014), a subject that deserves further investigation.

\subsubsection{Oligodendrocytes}

Although being extensively studied in other neurologic disorders, such as multiple sclerosis, the role of oligodendrocytes and myelin as targets and/or active players in the brain inflammatory response in aging and in AD has been clearly overlooked (Bartzokis, 2011; Roth et al., 2005). However, it was already shown that, in vitro, $\mathrm{A} \beta$ peptides with different sizes and under different states of aggregation are able to induce the death of oligodendrocytes in a dose-dependent manner and to prevent the formation of the myelin sheet (Horiuchi et al., 2012; Xu et al., 2001). These effects are attributed to increased NF- $\mathrm{KB}$ activation, mitochondrial dysfunction and cytoskeletal disintegration (Lee et al., 2004; Xu et al., 2001), and have also been observed in vivo, upon injection of $A \beta$ in the corpus callosum (which induced increased inflammation, microglial recruitment, oligodendrocyte toxicity and myelin and axonal damage) (Jantaratnotai et al., 2003). Moreover, there is evidence of oligodendrocyte loss and, thus, white matter deterioration, particularly in the core of amyloid plaques and in plaque-associated dystrophic neurites, but not in plaque-free neocortical areas, in the brains of both AD transgenic mice and of patients with familial and sporadic AD (Mitew et al., 2010). In addition, recent data also suggest that cerebral amyloidosis in AD mouse models is preceded by an impairment of neuronal networks and white matter structures, caused by an early soluble $A \beta$-driven oligodendrocyte dysfunction and myelin damage during pre-symptomatic stages (Desai et al., 2011; Grandjean et al., 2014). In fact, this effect may be attributed to increased levels of pro-inflammatory cytokines (e.g., TNF) and complement proteins (e.g., C1q, C3 and C4), which were shown to induce oligodendrocyte apoptosis and necrosis, respectively (Hosokawa et al., 2003; Louis et al., 1993). Moreover, increased levels of A $\beta$ peptides were shown to enhance the TNF-induced NOS2 expression and NO production in oligodendrocytes, which may in part explain the in vivo toxic effects of $A \beta$ on these glial cells (Zeng et al., 2005) (Fig. 3). Interestingly, it was reported that $A \beta$-mediated toxicity to oligodendrocytes is modulated by the presence of other glial cells in co-culture, namely astrocytes, which might be explained by the secretion of cell-specific factors that impact on the state of $A \beta$ aggregation and on the metabolism of $A \beta$ peptides (Ramirez et al., 2005; Roth et al., 2005). Protective or not, the presence, state of activation and survival of both astrocytes and microglia are critical for the early alterations in oligodendrocyte survival and white matter damage in the AD brain (Jantaratnotai et al., 2003; Kobayashi et al., 2002; Louis et al., 1993; Roth et al., 2005). 


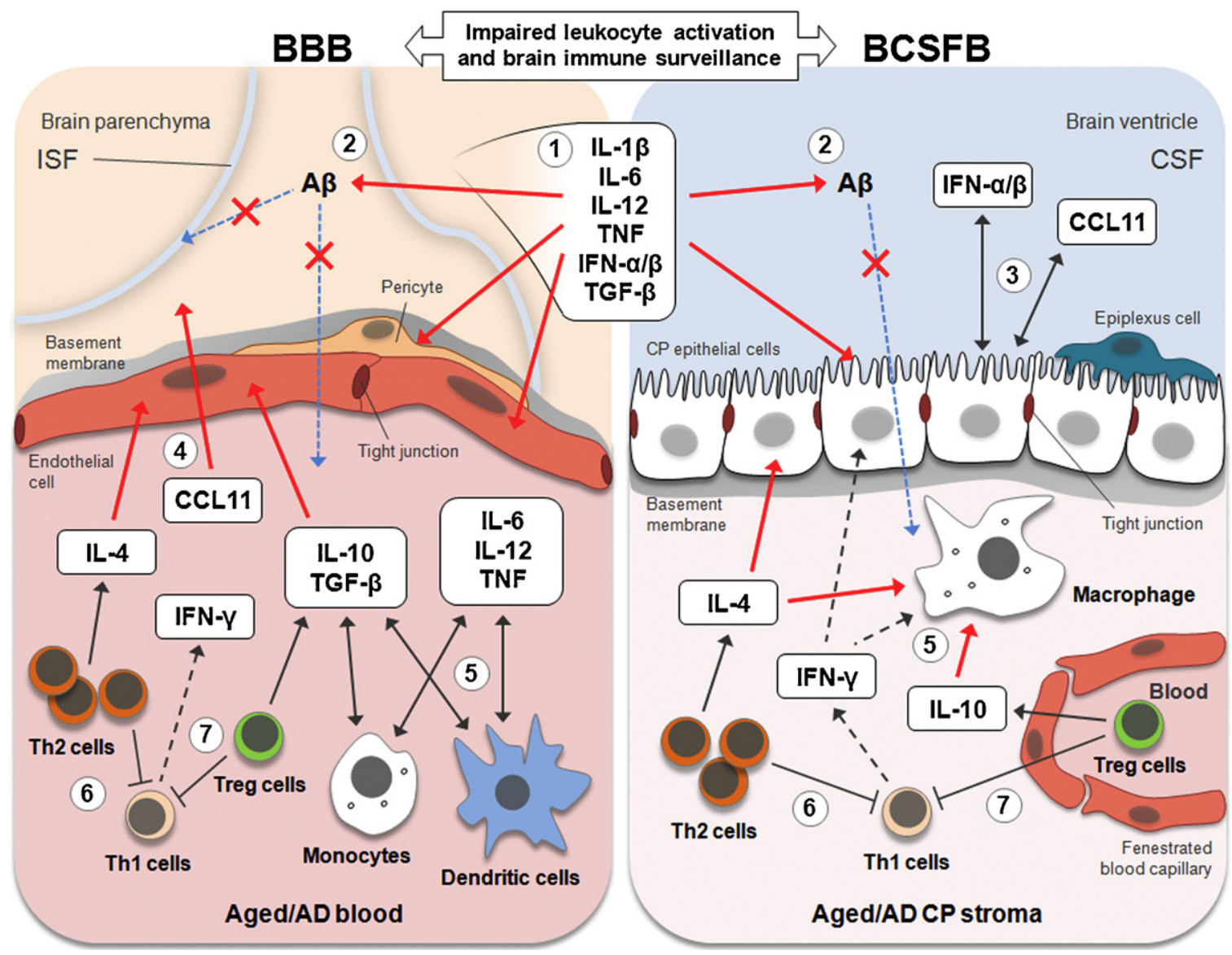

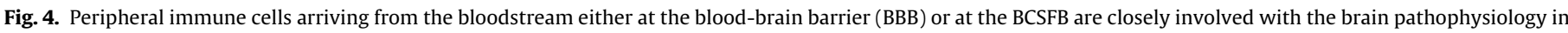

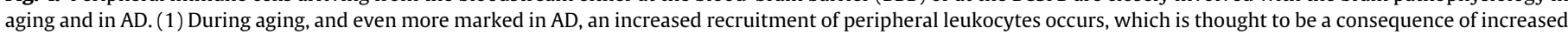

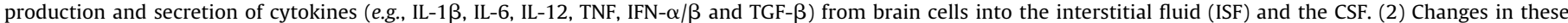

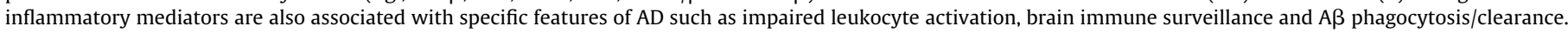

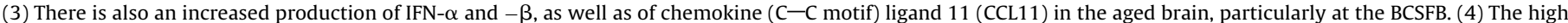

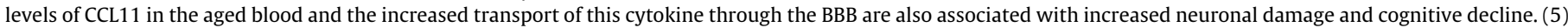

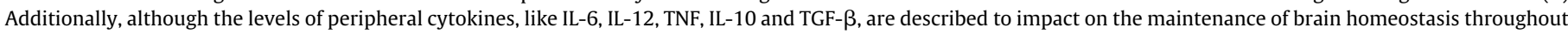

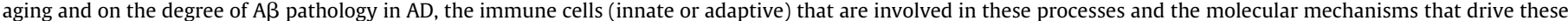

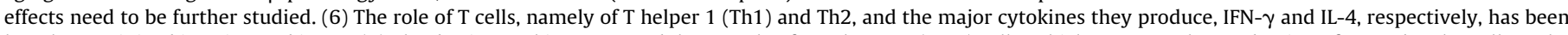

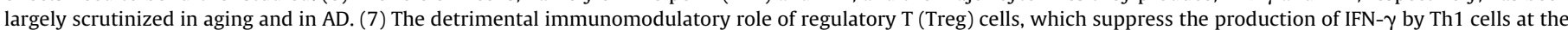

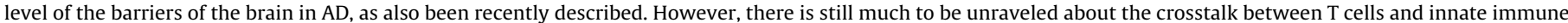

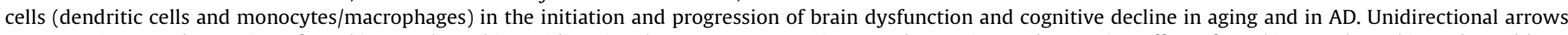

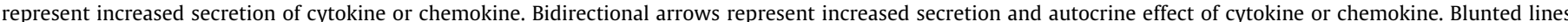

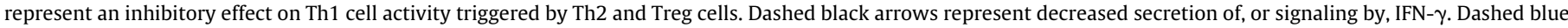

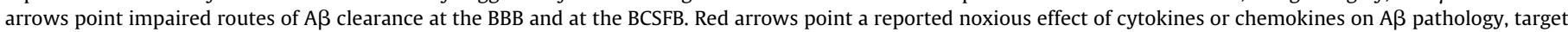
cell or tissue. (For interpretation of the references to colour in this figure legend, the reader is referred to the web version of this article.)

\section{The impact of the immune system on brain function in AD}

After the first evidence pointing to a role of adaptive immune cells on brain cognitive function (Kipnis et al., 2004), many studies in the past decade have emphasized the contribution of mediators of the immune system for the alterations in brain function observed in aging and in AD. In this section, we will analyze the role of specific cells of the innate and the adaptive immune systems and their impact in aging-induced cognitive deficits or even in brain pathology and behavioral changes in $\mathrm{AD}$ (Fig. 4). In fact, the recent discovery and characterization of CNS lymphatic vessels, which carry both fluid and immune cells from the CSF and are connected to the deep cervical lymph nodes (Aspelund et al., 2015; Louveau et al., $2015 b$ ), opens a new window on the possible functions of bone marrow-derived immune cells and of blood-borne molecules that, besides promoting $A \beta$ clearance, may also stimulate brain endogenous regenerative processes and improve the cognitive function in aging and in AD (Baruch and Schwartz, 2013; Katsumoto et al., 2014; Lucin and Wyss-Coray, 2009; Ransohoff, 2011) (Fig. 4).

Initial studies suggested that the induction of an $A \beta$-specific adaptive immune response could be the answer for an effective clearance of these toxic peptides out of the brain. This idea was strengthened by the positive effects of the active immunization with $A \beta$ peptides (Schenk et al., 1999), or of the injection of human $A \beta$-specific antibodies (Bard et al., 2000), on the disease phenotype of AD transgenic mice. These observations prompted for other studies, showing that the vaccination of AD transgenic mice with $A \beta$ peptides enhanced the peripheral levels of IL- 4 and IL- 10 , characteristic of a T helper 2 (Th2) response, and reduced the levels of IFN- $\gamma$, characteristic of a Th1 response (Town et al., 2002), being this shift responsible for a marked effect on the amyloid plaque load in 
the brain. However, despite proven useful in reducing brain amyloid load, and in rescuing behavioral deficits in mouse models of AD, most of the vaccination trials conducted on $A D$ patients resulted in moderate or no disease improvements and, even worse, in the aggravation of the cognitive deficits and in cases of meningoencephalitis (Holmes et al., 2008; Weiner and Frenkel, 2006). Several different approaches are now being developed in order to circumvent these problems, namely by altering the isotype of $A \beta$-specific antibodies in order to prevent the risk of Fc receptor-mediated over activation of microglia and the risk of vasogenic edema (Adolfsson et al., 2012). However, to date, no active or passive immunization approach has produced positive results on memory and cognition (Liu et al., 2015). Nevertheless, it is increasingly evident, from data presented in different studies, that immune cells play a critical role in the pathophysiology of AD. In line with this idea, it was shown that $A \beta$-specific Th2 cells transferred into AD transgenic mice, led to a reduction of pro-inflammatory cytokines such as IFN- $\gamma$, TNF and IL- 4 in the blood, which culminated in cognitive benefits, six weeks upon transfer (Cao et al., 2009). Concurrently, it was recently shown that, with aging, AD transgenic mice present a higher percentage of IFN- $\gamma$ - and IL-17-producing T cells in the brain (Browne et al., 2013; McManus et al., 2014). This increase in T cells may be a consequence of increased chemokine signaling, namely by CCL5 and CCR5, which were shown to be increased in the AD brain (Li et al., 2009; Tripathy et al., 2010). Moreover, the intravenous adoptive transfer of $A \beta$-specific Th1 cells, but not of $A \beta$-specific Th2 or Th17 cells, into AD transgenic mice led to increased levels of IFN- $\gamma$, microglial activation, cortical $A \beta$ accumulation and plaque burden and a worst cognitive performance (Browne et al., 2013). Interestingly, all the reported noxious effects of $A \beta$-specific Th1 cells were attenuated by repeated peripheral administration of an IFN- $\gamma$ blocking antibody (Browne et al., 2013). On the other hand, in the absence of any obvious CNS pathology, it was shown that an aging-associated increase in the percentage of recruited CNSspecific Th2 cells into the BCSFB can be extremely deleterious for normal brain function, due to their contribution to increased levels of IL-4 and CCL11 in the CSF (Fig. 4), which were shown to critically affect hippocampal neurogenesis and cognition (Baruch et al., 2013; Villeda et al., 2011). Additionally, as mentioned before, the increased levels of CCL11 in the blood and in the CSF may act on peripheral immune cells, on meningeal macrophages and on CNS-resident microglia, promoting their activation into a proinflammatory destructive phenotype (Baruch et al., 2013; Baruch and Schwartz, 2013). From these observations, the fine tuning of Th1/Th2 responses and the ratio IFN- $\gamma / \mathrm{IL}-4$, as well as the respective downstream molecules and signaling cascades, are thought to be very important for the proper functioning of the CNS (Baruch and Schwartz, 2013; Gadani et al., 2012) (Fig. 4). Interestingly, a recent study highlights a central role of regulatory $T$ cells on the development of pathology and cognitive impairment in $\mathrm{AD}$ (Baruch et al., 2015). Specifically, it was shown that the transient depletion of regulatory $T$ cells at the periphery ultimately impacts on the number of IFN- $\gamma$-positive cells at the BCSFB, leading to a protective neuroinflammatory response in the brain, decreased $\mathrm{A} \beta$ plaque load and better cognitive performance (Baruch et al., 2015).

Besides $\mathrm{T}$ cells, other peripheral immune cells were shown to modulate brain function in $\mathrm{AD}$, namely dendritic cells and monocytes/macrophages (Schwartz et al., 2013). Still following the idea of peripheral immune cell activation for CNS repair, treatment with glatiramer acetate, a known promoter of Th2-based immune responses, was able to induce an IL-4-dependent change in microglial phenotype and the mobilization of bone marrowderived $\mathrm{CD} 11 \mathrm{C}^{+}$dendritic cells into the brain, which favored the clearance of parenchymal $A \beta$ deposits in a mouse model of $A D$ (Butovsky et al., 2006). The beneficial effect of increased num- ber of $\mathrm{CD} 11 \mathrm{C}^{+}$cells in the brain was associated with an increased production of the neurotrophic factor IGF-1, which may be in part responsible for the observed stimulation of neurogenesis and attenuated cognitive decline in the glatiramer acetate-treated $\mathrm{AD}$ transgenic mice (Butovsky et al., 2007a,b, 2006), and also for increased clearance of $A \beta$ through the BCSFB (Carro et al., 2005, 2002). Furthermore, blocking TGF- $\beta$ signaling in $C^{2} 11 C^{+}$innate immune cells increased the recruitment of circulating monocytes into the brain, which in turn are able to remove $A \beta$ from the brain vasculature, decreasing the degree of cerebral amyloid angiopathy and parenchymal $A \beta$ deposition, and modestly improve cognitive function in an AD transgenic mouse model (Michaud et al., 2013a; Town et al., 2008). Interestingly, these effects were also accompanied by an up-regulated expression of the gene encoding for IL-10, suggesting that, besides their function in $A \beta$ clearance and increased neurogenesis, these bone marrow-derived antigen presenting cells may also have an important immunosupressive role in the AD brain (Town et al., 2008). Noticeably, it was recently proposed that peripheral monocytes have more functional consequences on $\mathrm{AD}$-associated traits, when compared to other peripheral cells of lymphoid origin, namely $\mathrm{CD} 4^{+} \mathrm{T}$ cells (Raj et al., 2014). In agreement, several studies using mouse models of $\mathrm{AD}$ have shown that, after whole-body irradiation and immune reconstitution, bone marrow-derived cells of myeloid origin are able to infiltrate the brain in regions of increased $A \beta$ deposition and where the BBB is more permeable (Simard et al., 2006; Stalder et al., 2005). Moreover, immune system reconstitution of an $\mathrm{AD}$ transgenic mouse model with strain-matched bone marrow cells from healthy wild-type donor mice promoted a shift into a Th2 profile of cytokine expression, which was responsible for increased recruitment of monocytes/macrophages into the brain and $A \beta$ phagocytosis by recruited macrophages and resident microglia (Zhu et al., 2011). These myeloid cells were able to differentiate into brain perivascular macrophages and microglia, contributing to the clearance of $A \beta$ from the brain vasculature and parenchyma, respectively (Michaud et al., 2013a; Mildner et al., 2011; Simard et al., 2006). Accordingly, impaired CCL2 signaling by ablation of its receptor, CCR2, was shown to accelerate memory loss and brain pathology in a mouse model of $\mathrm{AD}$; an effect that was attributed to a decreased recruitment of peripheral monocyte-like cells, shown to differentiate into competent $A \beta$-internalizing microglia (El Khoury et al., 2007; Naert and Rivest, 2011; Varvel et al., 2012). Of interest, and as already mentioned for microglia, the activation state of the recruited peripheral monocytes/macrophages may also be a limiting step in AD pathology (Fig. 4). Monocytes also express different TLRs, namely TLR2 and TLR4 which, besides their ability to recognize $A \beta$ peptides, regulate the process of $A \beta$ phagocytosis upon stimulation (Michaud et al., 2013b; Richard et al., 2008). However, monocytes isolated from AD patients presented lower expression levels of different TLRs, which was associated with a decreased phagocytosis and lysosomal degradation of $A \beta$, when compared to monocytes from age-matched healthy subjects (Fiala et al., 2007). Altogether, these findings strongly support the relevance of multiple peripheral immune cells, particularly of innate-like cells of myeloid origin, and their function in brain immune surveillance and repair in AD. Moreover, given that resident glial cells have a limited capacity for $A \beta$ phagocytosis in $A D$, specially upon plaque assembly (Meyer-Luehmann et al., 2008; WyssCoray et al., 2003), understanding the mechanisms that modulate the recruitment and entry of peripheral bone marrow-derived monocytes into the brain, and differentiation into microglial-like cells, is important to propose strategies to reduce the agedependent increased brain vascular and parenchymal amyloid burden. 


\section{Concluding remarks}

The pathophysiology of AD results, at least in part, from changes in $A \beta$ formation and accumulation in the brain. Yet, the activation of the amyloidogenic pathway and the neuroinflammatory response, both at the brain barriers and at the brain parenchyma, cannot be dissociated. In sum, there seems to be a duality concerning inflammatory glial and neuronal activation, in which the beneficial or detrimental effects can easily overlap and depend on the nature of the molecular mediators produced by brain cells and their respective autocrine and/or paracrine effects, as well as the timing of occurrence. While some immune cells and inflammatory mediators, from the periphery, potentially exacerbate brain damage, others orchestrate mechanisms of $A \beta$ clearance, brain repair and regeneration. Importantly, when properly stimulated, peripheral immune cells can also actively contribute to the regulation of the neuroinflammatory response and to the modulation of brain function and behavior, by interacting with the cells that compose the barriers of the brain and, in some cases, with brain parenchymal cells. However, besides all the advances made so far, more studies are needed in order to fully understand the role of specific populations of immune cells and other modulators of the inflammatory response on the aging process of the brain, under healthy conditions and in the context of AD.

\section{Conflict of interest}

The authors have no conflicting financial interests to declare.

\section{Acknowledgments}

Sandro Dá Mesquita is recipient of a research fellowship by the Fundação Calouste Gulbenkian (Programa Gulbenkian Inovar em Saúde), with the reference UMINHO/BI/155/2015. Ana C. Ferreira is recipient of a $\mathrm{PhD}$ fellowship by the Fundação para a Ciência e Tecnologia (FCT, Portugal)/FEDER and Programa Operacional Potencial Humano (POPH/FSE), with the reference SFRH/BD/51989/2012. Fernanda Marques is an assistant researcher and recipient of a FCT Investigator grant with the reference IF/00231/2013. This work was supported by FCT and COMPETE through the project EXPL/NEUOSD/2196/2013 and the Bial Foundation through the Grant 217/12.

\section{References}

Abramov, A.Y., Canevari, L., Duchen, M.R., 2004. Beta-amyloid peptides induce mitochondrial dysfunction and oxidative stress in astrocytes and death of neurons through activation of NADPH oxidase. J. Neurosci. 24, 565-575.

Adolfsson, O., Pihlgren, M., Toni, N., Varisco, Y., Buccarello, A.L., et al., 2012. An effector-reduced anti-beta-amyloid (Abeta) antibody with unique abeta binding properties promotes neuroprotection and glial engulfment of Abeta. J. Neurosci. 32, 9677-9689.

Akama, K.T., Albanese, C., Pestell, R.G., Van Eldik, L.J., 1998. Amyloid beta-peptide stimulates nitric oxide production in astrocytes through an NFkappaB-dependent mechanism. Proc. Natl. Acad. Sci. U. S. A. 95, 5795-5800.

Albert, M.S., DeKosky, S.T., Dickson, D., Dubois, B., Feldman, H.H., et al., 2011. The diagnosis of mild cognitive impairment due to Alzheimer's disease: recommendations from the National Institute on Aging-Alzheimer's Association workgroups on diagnostic guidelines for Alzheimer's disease. Alzheimers Dement. 7, 270-279.

Albert, M.S., 1996. Cognitive and neurobiologic markers of early Alzheimer disease. Proc. Natl. Acad. Sci. U. S. A. 93, 13547-13551.

Andrieu, S., Coley, N., Lovestone, S., Aisen, P.S., Vellas, B., 2015. Prevention of sporadic Alzheimer's disease: lessons learned from clinical trials and future directions. Lancet Neurol. 14, 926-944.

Armulik, A., Genove, G., Mae, M., Nisancioglu, M.H., Wallgard, E., et al., 2010. Pericytes regulate the blood-brain barrier. Nature 468, 557-561.

Aspelund, A., Antila, S., Proulx, S.T., Karlsen, T.V., Karaman, S., et al., 2015. A dural lymphatic vascular system that drains brain interstitial fluid and macromolecules. J. Exp. Med. 212, 991-999.

Avila-Munoz, E., Arias, C., 2014. When astrocytes become harmful: functional and inflammatory responses that contribute to Alzheimer's disease. Ageing Res. Rev. 18, 29-40.
Ballard, C., Gauthier, S., Corbett, A., Brayne, C., Aarsland, D., et al., 2011. Alzheimer's disease. Lancet 377, 1019-1031.

Banks, W.A., 2015. The blood-brain barrier in neuroimmunology: tales of separation and assimilation. Brain Behav. Immun. 44, 1-8.

Bard, F., Cannon, C., Barbour, R., Burke, R.L., Games, D., et al., 2000. Peripherally administered antibodies against amyloid beta-peptide enter the central nervous system and reduce pathology in a mouse model of Alzheimer disease. Nat. Med. 6, 916-919.

Baron, R., Babcock, A.A., Nemirovsky, A., Finsen, B., Monsonego, A., 2014. Accelerated microglial pathology is associated with Abeta plaques in mouse models of Alzheimer's disease. Aging Cell 13, 584-595.

Bartzokis, G., 2011. Alzheimer's disease as homeostatic responses to age-related myelin breakdown. Neurobiol. Aging 32, 1341-1371.

Baruch, K., Schwartz, M., 2013. CNS-specific T cells shape brain function via the choroid plexus. Brain Behav. Immun. 34, 11-16.

Baruch, K., Ron-Harel, N., Gal, H., Deczkowska, A., Shifrut, E., et al., 2013. CNS-specific immunity at the choroid plexus shifts toward destructive Th2 inflammation in brain aging. Proc. Natl. Acad. Sci. U. S. A. 110, 2264-2269.

Baruch, K., Deczkowska, A., David, E., Castellano, J.M., Miller, O., et al., 2014. Aging: aging-induced type I interferon response at the choroid plexus negatively affects brain function. Science $346,89-93$.

Baruch, K., Rosenzweig, N., Kertser, A., Deczkowska, A., Sharif, A.M., et al., 2015. Breaking immune tolerance by targeting Foxp3(+) regulatory T cells mitigates Alzheimer's disease pathology. Nat. Commun. 6, 7967.

Bateman, R.J., Xiong, C., Benzinger, T.L., Fagan, A.M., Goate, A., et al., 2012. Clinical and biomarker changes in dominantly inherited Alzheimer's disease. N. Engl. J. Med. 367, 795-804.

Begley, D.J., Brightman, M.W., 2003. Structural and functional aspects of the blood-brain barrier. Prog. Drug Res. 61, 39-78.

Bell, R.D., Winkler, E.A., Singh, I., Sagare, A.P., Deane, R., et al., 2012. Apolipoprotein E controls cerebrovascular integrity via cyclophilin A. Nature 485, 512-516.

Benilova, I., Karran, E., De Strooper, B., 2012. The toxic Abeta oligomer and Alzheimer's disease: an emperor in need of clothes. Nat. Neurosci. 15, 349-357.

Bhaskar, K., Maphis, N., Xu, G., Varvel, N.H., Kokiko-Cochran, O.N., et al., 2014. Microglial derived tumor necrosis factor-alpha drives Alzheimer's disease-related neuronal cell cycle events. Neurobiol. Dis. 62, 273-285.

Bi, F., Huang, C., Tong, J., Qiu, G., Huang, B., et al., 2013. Reactive astrocytes secrete lcn2 to promote neuron death. Proc. Natl. Acad. Sci. U. S. A. 110, 4069-4074.

Bierhaus, A., Illmer, T., Kasper, M., Luther, T., Quehenberger, P., et al., 1997. Advanced glycation end product (AGE)-mediated induction of tissue factor in cultured endothelial cells is dependent on RAGE. Circulation 96, 2262-2271.

Blasko, I., Veerhuis, R., Stampfer-Kountchev, M., Saurwein-Teissl, M., Eikelenboom, P., et al., 2000. Costimulatory effects of interferon-gamma and interleukin-1beta or tumor necrosis factor alpha on the synthesis of Abeta1-40 and Abeta1-42 by human astrocytes. Neurobiol. Dis. 7, 682-689.

Bonaiuto, C., McDonald, P.P., Rossi, F., Cassatella, M.A., 1997. Activation of nuclear factor-kappa B by beta-amyloid peptides and interferon-gamma in murine microglia. J. Neuroimmunol. 77, 51-56.

Brightman, M.W., Reese, T.S., 1969. Junctions between intimately apposed cell membranes in the vertebrate brain. J. Cell Biol. 40, 648-677.

Britschgi, M., Takeda-Uchimura, Y., Rockenstein, E., Johns, H., Masliah, E., et al. 2012. Deficiency of terminal complement pathway inhibitor promotes neuronal tau pathology and degeneration in mice. J. Neuroinflammation 9, 220

Browne, T.C., McQuillan, K., McManus, R.M., O’Reilly, J.A., Mills, K.H., et al., 2013. IFN-gamma Production by amyloid beta-specific Th1 cells promotes microglial activation and increases plaque burden in a mouse model of Alzheimer's disease. J. Immunol. 190, 2241-2251.

Bush, T.G., Puvanachandra, N., Horner, C.H., Polito, A, Ostenfeld, T, et al., 1999. Leukocyte infiltration, neuronal degeneration, and neurite outgrowth after ablation of scar-forming, reactive astrocytes in adult transgenic mice. Neuron 23, 297-308.

Butovsky, O., Koronyo-Hamaoui, M., Kunis, G., Ophir, E., Landa, G., et al., 2006. Glatiramer acetate fights against Alzheimer's disease by inducing dendritic-like microglia expressing insulin-like growth factor 1. Proc. Natl. Acad. Sci. U. S. A. 103, 11784-11789.

Butovsky, O., Bukshpan, S., Kunis, G., Jung, S., Schwartz, M., 2007a. Microglia can be induced by IFN-gamma or IL-4 to express neural or dendritic-like markers. Mol. Cell. Neurosci. 35, 490-500.

Butovsky, O., Kunis, G., Koronyo-Hamaoui, M., Schwartz, M., 2007b. Selective ablation of bone marrow-derived dendritic cells increases amyloid plaques in a mouse Alzheimer's disease model. Eur. J. Neurosci. 26, 413-416.

Cameron, B., Landreth, G.E., 2010. Inflammation, microglia, and Alzheimer's disease. Neurobiol. Dis. 37, 503-509.

Cao, C., Arendash, G.W., Dickson, A., Mamcarz, M.B., Lin, X., et al., 2009. Abeta-specific Th2 cells provide cognitive and pathological benefits to Alzheimer's mice without infiltrating the CNS. Neurobiol. Dis. 34, 63-70.

Carrero, I., Gonzalo, M.R., Martin, B., Sanz-Anquela, J.M., Arevalo-Serrano, J., et al., 2012. Oligomers of beta-amyloid protein (Abeta1-42) induce the activation of cyclooxygenase- 2 in astrocytes via an interaction with interleukin-1beta, tumour necrosis factor-alpha, and a nuclear factor kappa-B mechanism in the rat brain. Exp. Neurol. 236, 215-227.

Carro, E., Trejo, J.L., Gomez-Isla, T., LeRoith, D., Torres-Aleman, I., 2002. Serum insulin-like growth factor I regulates brain amyloid-beta levels. Nat. Med. 8, 1390-1397. 
Carro, E., Spuch, C., Trejo, J.L., Antequera, D., Torres-Aleman, I., 2005. Choroid plexus megalin is involved in neuroprotection by serum insulin-like growth factor I. J. Neurosci. 25, 10884-10893.

Castellani, R.J., Lee, H.G., Zhu, X., Perry, G., Smith, M.A., 2008. Alzheimer disease pathology as a host response. J. Neuropathol. Exp. Neurol. 67, 523-531.

Chakrabarty, P., Ceballos-Diaz, C., Beccard, A., Janus, C., Dickson, D., et al., 2010a. IFN-gamma promotes complement expression and attenuates amyloid plaque deposition in amyloid beta precursor protein transgenic mice. J. Immunol. 184, 5333-5343.

Chakrabarty, P., Jansen-West, K., Beccard, A., Ceballos-Diaz, C., Levites, Y., et al., 2010b. Massive gliosis induced by interleukin-6 suppresses Abeta deposition in vivo: evidence against inflammation as a driving force for amyloid deposition. FASEB J. 24, 548-559.

Chakrabarty, P., Herring, A., Ceballos-Diaz, C., Das, P., Golde, T.E., 2011 Hippocampal expression of murine TNFalpha results in attenuation of amyloid deposition in vivo. Mol. Neurodegener. 6, 16.

Chakrabarty, P., Tianbai, L., Herring, A., Ceballos-Diaz, C., Das, P., et al., 2012. Hippocampal expression of murine IL-4 results in exacerbation of amyloid deposition. Mol. Neurodegener. 7, 36.

Chakrabarty, P., Li, A., Ceballos-Diaz, C., Eddy, J.A., Funk, C.C., et al., 2015. IL-10 alters immunoproteostasis in APP mice, increasing plaque burden and worsening cognitive behavior. Neuron 85, 519-533.

Chalbot, S., Zetterberg, H., Blennow, K., Fladby, T., Andreasen, N., et al., 2011. Blood-cerebrospinal fluid barrier permeability in Alzheimer's disease. J. Alzheimers Dis. 25, 505-515.

Chen, X., Walker, D.G., Schmidt, A.M., Arancio, O., Lue, L.F., et al., 2007. RAGE: a potential target for Abeta-mediated cellular perturbation in Alzheimer's disease. Curr. Mol. Med. 7, 735-742.

Combs, C.K., Karlo, J.C., Kao, S.C., Landreth, G.E., 2001. beta-Amyloid stimulation of microglia and monocytes results in TNFalpha-dependent expression of inducible nitric oxide synthase and neuronal apoptosis. J. Neurosci. 21, 1179-1188.

Corder, E.H., Saunders, A.M., Strittmatter, W.J., Schmechel, D.E., Gaskell, P.C., et al., 1993. Gene dose of apolipoprotein E type 4 allele and the risk of Alzheimer's disease in late onset families. Science 261, 921-923.

Cornell-Bell, A.H., Finkbeiner, S.M., Cooper, M.S., Smith, S.J., 1990. Glutamate induces calcium waves in cultured astrocytes: long-range glial signaling. Science $247,470-473$.

Cras, P., Kawai, M., Lowery, D., Gonzalez-DeWhitt, P., Greenberg B., et al., 1991. Senile plaque neurites in Alzheimer disease accumulate amyloid precursor protein. Proc. Natl. Acad. Sci. U. S. A. 88, 7552-7556.

Damoiseaux, J.S., Rombouts, S.A., Barkhof, F., Scheltens, P., Stam, C.J., et al., 2006. Consistent resting-state networks across healthy subjects. Proc. Natl. Acad. Sci. U. S. A. 103, 13848-13853.

Deane, R., Du Yan, S., Submamaryan, R.K., LaRue, B., Jovanovic, S., et al., 2003. RAGE mediates amyloid-beta peptide transport across the blood-brain barrier and accumulation in brain. Nat. Med. 9, 907-913.

Deane, R., Wu, Z., Sagare, A., Davis, J., Du Yan, S., et al., 2004. LRP/amyloid beta-peptide interaction mediates differential brain efflux of Abeta isoforms. Neuron 43, 333-344.

Deane, R., Sagare, A., Hamm, K., Parisi, M., Lane, S., et al., 2008. apoE isoform-specific disruption of amyloid beta peptide clearance from mouse brain. J. Clin. Invest. 118, 4002-4013.

Desai, M.K., Guercio, B.J., Narrow, W.C., Bowers, W.J., 2011. An Alzheimer's disease-relevant presenilin-1 mutation augments amyloid-beta-induced oligodendrocyte dysfunction. Glia 59, 627-640.

Devireddy, L.R., Gazin, C., Zhu, X., Green, M.R., 2005. A cell-surface receptor for lipocalin $24 \mathrm{p} 3$ selectively mediates apoptosis and iron uptake. Cell 123, 1293-1305.

Du Yan, S., Zhu, H., Fu, J., Yan, S.F., Roher, A., et al., 1997. Amyloid-beta peptide-receptor for advanced glycation endproduct interaction elicits neuronal expression of macrophage-colony stimulating factor: a proinflammatory pathway in Alzheimer disease. Proc. Natl. Acad. Sci. U. S. A. $94,5296-5301$

Edbauer, D., Winkler, E., Regula, J.T., Pesold, B., Steiner, H., et al., 2003. Reconstitution of gamma-secretase activity. Nat. Cell Biol. 5, 486-488.

Ek, C.J., Habgood, M.D., Dziegielewska, K.M., Saunders, N.R., 2003. Structural characteristics and barrier properties of the choroid plexuses in developing brain of the opossum (Monodelphis Domestica). J. Comp. Neurol. 460, 451-464.

El Khoury, J.B., Moore, K.J., Means, T.K., Leung, J., Terada, K., et al., 2003. CD36 mediates the innate host response to beta-amyloid. J. Exp. Med. 197, 1657-1666.

El Khoury, J., Toft, M., Hickman, S.E., Means, T.K., Terada, K., et al., 2007. Ccr2 deficiency impairs microglial accumulation and accelerates progression of Alzheimer-like disease. Nat. Med. 13, 432-438.

Elmore, M.R., Najafi, A.R., Koike, M.A., Dagher, N.N., Spangenberg, E.E., et al., 2014. Colony-stimulating factor 1 receptor signaling is necessary for microglia viability, unmasking a microglia progenitor cell in the adult brain. Neuron 82 380-397.

Engelhardt, B., Wolburg-Buchholz, K., Wolburg, H., 2001. Involvement of the choroid plexus in central nervous system inflammation. Microsc. Res. Tech. 52, $112-129$.

Engler, H., Forsberg, A., Almkvist, O., Blomquist, G., Larsson, E., et al., 2006. Two-year follow-up of amyloid deposition in patients with Alzheimer's disease. Brain: J. Neurol. 129, 2856-2866.
Erickson, M.A., Hansen, K., Banks, W.A., 2012a. Inflammation-induced dysfunction of the low-density lipoprotein receptor-related protein-1 at the blood-brain barrier: protection by the antioxidant $\mathrm{N}$-acetylcysteine. Brain Behav. Immun. 26, 1085-1094.

Erickson, M.A., Hartvigson, P.E., Morofuji, Y., Owen, J.B., Butterfield, D.A., et al., 2012b. Lipopolysaccharide impairs amyloid beta efflux from brain: altered vascular sequestration, cerebrospinal fluid reabsorption, peripheral clearance and transporter function at the blood-brain barrier. J. Neuroinflammation 9 , 150.

Erickson, M.A., Morofuji, Y., Owen, J.B., Banks, W.A., 2014. Rapid transport of CCL11 across the blood-brain barrier: regional variation and importance of blood cells. J. Pharmacol. Exp. Ther. 349, 497-507.

Faden, A.I., Loane, D.J., 2015. Chronic neurodegeneration after traumatic brain injury: Alzheimer disease, chronic traumatic encephalopathy, or persistent neuroinflammation? Neurotherapeutics 12, 143-150.

Fagan, A.M., Mintun, M.A., Mach, R.H., Lee, S.Y., Dence, C.S., et al., 2006. Inverse relation between in vivo amyloid imaging load and cerebrospinal fluid Abeta42 in humans. Ann. Neurol. 59, 512-519.

Fagan, A.M., Head, D., Shah, A.R., Marcus, D., Mintun, M., et al., 2009. Decreased cerebrospinal fluid Abeta(42) correlates with brain atrophy in cognitively normal elderly. Ann. Neurol. 65, 176-183.

Fagan, A.M., Xiong, C., Jasielec, M.S., Bateman, R.J., Goate, A.M., et al., 2014. Longitudinal change in CSF biomarkers in autosomal-dominant Alzheimer's disease. Sci. Transl. Med. 6, 226ra230.

Fiala, M., Liu, P.T., Espinosa-Jeffrey, A., Rosenthal, M.J., Bernard, G., et al., 2007. Innate immunity and transcription of MGAT-III and Toll-like receptors in Alzheimer's disease patients are improved by bisdemethoxycurcumin. Proc. Natl. Acad. Sci. U. S. A. 104, 12849-12854.

Flo, T.H., Smith, K.D., Sato, S., Rodriguez, D.J., Holmes, M.A., et al., 2004. Lipocalin 2 mediates an innate immune response to bacterial infection by sequestrating iron. Nature 432, 917-921.

Fuhrmann, M., Bittner, T., Jung, C.K., Burgold, S., Page, R.M., et al., 2010. Microglial Cx3cr1 knockout prevents neuron loss in a mouse model of Alzheimer's disease. Nat. Neurosci. 13, 411-413.

Furman, J.L., Sama, D.M., Gant, J.C., Beckett, T.L., Murphy, M.P., et al., 2012. Targeting astrocytes ameliorates neurologic changes in a mouse model of Alzheimer's disease. J. Neurosci. 32, 16129-16140.

Gabuzda, D., Yankner, B.A., 2013. Physiology: inflammation links ageing to the brain. Nature 497, 197-198.

Gadani, S.P., Cronk, J.C., Norris, G.T., Kipnis, J., 2012. IL-4 in the brain: a cytokine to remember. J. Immunol. 189, 4213-4219.

Garwood, C.J., Pooler, A.M., Atherton, J., Hanger, D.P., Noble, W., 2011. Astrocytes are important mediators of Abeta-induced neurotoxicity and tau phosphorylation in primary culture. Cell. Death. Dis. 2, e167.

Ghosh, S., Wu, M.D., Shaftel, S.S., Kyrkanides, S., LaFerla, F.M., et al., 2013. Sustained interleukin-1beta overexpression exacerbates tau pathology despite reduced amyloid burden in an Alzheimer's mouse model. J. Neurosci. 33, 5053-5064.

Girouard, H., Iadecola, C., 2006. Neurovascular coupling in the normal brain and in hypertension, stroke, and Alzheimer disease. J. Appl. Physiol. (1985) 100, 328-335.

Goate, A., Chartier-Harlin, M.C., Mullan, M., Brown, J., Crawford, F., et al., 1991. Segregation of a missense mutation in the amyloid precursor protein gene with familial Alzheimer's disease. Nature 349, 704-706.

Gordon, G.R., Mulligan, S.J., MacVicar, B.A., 2007. Astrocyte control of the cerebrovasculature. Glia 55, 1214-1221.

Gotz, J., Chen, F., van Dorpe, J., Nitsch, R.M., 2001. Formation of neurofibrillary tangles in P301l tau transgenic mice induced by Abeta 42 fibrils. Science 293 1491-1495.

Grandjean, J., Schroeter, A., He, P., Tanadini, M., Keist, R., et al., 2014. Early alterations in functional connectivity and white matter structure in a transgenic mouse model of cerebral amyloidosis. J. Neurosci. 34, 13780-13789.

Greenberg, S.M., Gurol, M.E., Rosand, J., Smith, E.E., 2004. Amyloid angiopathy-related vascular cognitive impairment. Stroke 35, 2616-2619.

Griffin, W.S., 2013. Neuroinflammatory cytokine signaling and Alzheimer's disease N. Engl. J. Med. 368, 770-771.

Gu, Y., Misonou, H., Sato, T., Dohmae, N., Takio, K., et al., 2001. Distinct intramembrane cleavage of the beta-amyloid precursor protein family resembling gamma-secretase-like cleavage of Notch. J. Biol. Chem. 276 35235-35238.

Guillot-Sestier, M.V., Doty, K.R., Gate, D., Rodriguez Jr., J., Leung, B.P., et al., 2015. Il10 deficiency rebalances innate immunity to mitigate Alzheimer-like pathology. Neuron 85, 534-548.

Haass, C., Selkoe, D.J., 2007. Soluble protein oligomers in neurodegeneration: lessons from the Alzheimer's amyloid beta-peptide. Nat. Rev. Mol. Cell Biol. 8, 101-112.

Halassa, M.M., Haydon, P.G., 2010. Integrated brain circuits: astrocytic networks modulate neuronal activity and behavior. Annu. Rev. Physiol. 72, 335-355.

Halassa, M.M., Fellin, T., Takano, H., Dong, J.H., Haydon, P.G., 2007. Synaptic islands defined by the territory of a single astrocyte. J. Neurosci. 27, 6473-6477.

Hansson, O., Zetterberg, H., Buchhave, P., Londos, E., Blennow, K., et al., 2006. Association between CSF biomarkers and incipient Alzheimer's disease in patients with mild cognitive impairment: a follow-up study. Lancet Neurol. 5, 228-234.

Hardy, J.A., Higgins, G.A., 1992. Alzheimer's disease: the amyloid cascade hypothesis. Science $256,184-185$. 
Hardy, J., Selkoe, D.J., 2002. The amyloid hypothesis of Alzheimer's disease: progress and problems on the road to therapeutics. Science 297, 353-356.

Hartz, A.M., Zhong, Y., Wolf, A., LeVine 3rd, H., Miller, D.S., et al., 2016. Abeta40 reduces P-glycoprotein at the blood-brain barrier through the ubiquitin-proteasome pathway. J. Neurosci. 36, 1930-1941.

Hasegawa-Ishii, S., Shimada, A., Inaba, M., Li, M., Shi, M., et al., 2013. Selective localization of bone marrow-derived ramified cells in the brain adjacent to the attachments of choroid plexus. Brain Behav. Immun. 29, 82-97.

Henneberger, C., Papouin, T., Oliet, S.H., Rusakov, D.A., 2010. Long-term potentiation depends on release of D-serine from astrocytes. Nature 463, 232-236.

Holmes, C., Boche, D., Wilkinson, D., Yadegarfar, G., Hopkins, V., et al., 2008. Long-term effects of Abeta42 immunisation in Alzheimer's disease: follow-up of a randomised, placebo-controlled phase I trial. Lancet 372, 216-223.

Hong, S., Quintero-Monzon, O., Ostaszewski, B.L., Podlisny, D.R., Cavanaugh, W.T., et al., 2011. Dynamic analysis of amyloid beta-protein in behaving mice reveals opposing changes in ISF versus parenchymal Abeta during age-related plaque formation. J. Neurosci. 31, 15861-15869.

Horiuchi, M., Maezawa, I., Itoh, A., Wakayama, K., Jin, L.W., et al., 2012. Amyloid beta1-42 oligomer inhibits myelin sheet formation in vitro. Neurobiol. Aging 33, 499-509.

Hosokawa, M., Klegeris, A., Maguire, J., McGeer, P.L., 2003. Expression of complement messenger RNAs and proteins by human oligodendroglial cells. Glia 42, 417-423.

Hsiao, K., Chapman, P., Nilsen, S., Eckman, C., Harigaya, Y., et al., 1996. Correlative memory deficits, Abeta elevation, and amyloid plaques in transgenic mice. Science 274, 99-102.

Hsiao, H.Y., Mak, O.T., Yang, C.S., Liu, Y.P., Fang, K.M., et al., 2007. TNF-alpha/IFN-gamma-induced iNOS expression increased by prostaglandin E2 in rat primary astrocytes via EP2-evoked cAMP/PKA and intracellular calcium signaling. Glia 55, 214-223.

Hsieh, C.L., Koike, M., Spusta, S.C., Niemi, E.C., Yenari, M., et al., 2009. A role for TREM2 ligands in the phagocytosis of apoptotic neuronal cells by microglia. J. Neurochem. 109, 1144-1156.

Hurtado-Alvarado, G., Cabanas-Morales, A.M., Gomez-Gonzalez, B., 2014. Pericytes: brain-immune interface modulators. Front. Integr. Neurosci. 7, 80.

Iadecola, C., Nedergaard, M., 2007. Glial regulation of the cerebral microvasculature. Nat. Neurosci. 10, 1369-1376.

Iadecola, C., 2004. Neurovascular regulation in the normal brain and in Alzheimer's disease. Nat. Rev. Neurosci. 5, 347-360.

Iliff, J.J., Wang, M., Liao, Y., Plogg, B.A., Peng, W., et al., 2012. A paravascular pathway facilitates CSF flow through the brain parenchyma and the clearance of interstitial solutes, including amyloid beta. Sci. Transl. Med. 4, 147ra111.

Jang, E., Kim, J.H., Lee, S., Kim, J.H., Seo, J.W., et al., 2013a. Phenotypic polarization of activated astrocytes: the critical role of lipocalin-2 in the classical inflammatory activation of astrocytes. J. Immunol. 191, 5204-5219.

Jang, E., Lee, S., Kim, J.H., Kim, J.H., Seo, J.W., et al., 2013b. Secreted protein lipocalin-2 promotes microglial M1 polarization. FASEB J. 27, 1176-1190.

Jansson, D., Rustenhoven, J., Feng, S., Hurley, D., Oldfield, R.L., et al., 2014. A role for human brain pericytes in neuroinflammation. J. Neuroinflammation 11, 104.

Jantaratnotai, N., Ryu, J.K., Kim, S.U., McLarnon, J.G., 2003. Amyloid beta peptide-induced corpus callosum damage and glial activation in vivo. Neuroreport 14, 1429-1433.

Johansson, P.A., Dziegielewska, K.M., Liddelow, S.A., Saunders, N.R., 2008. The blood-CSF barrier explained: when development is not immaturity. Bioessays 30, 237-248.

Johansson, J.U., Woodling, N.S., Wang, Q., Panchal, M., Liang, X., et al., 2015. Prostaglandin signaling suppresses beneficial microglial function in Alzheimer's disease models. J. Clin. Invest. 125, 350-364.

Kamenetz, F., Tomita, T., Hsieh, H., Seabrook, G., Borchelt, D., et al., 2003. APP processing and synaptic function. Neuron 37, 925-937.

Kamphuis, W., Middeldorp, J., Kooijman, L., Sluijs, J.A., Kooi, E.J., et al., 2014. Glial fibrillary acidic protein isoform expression in plaque related astrogliosis in Alzheimer's disease. Neurobiol. Aging 35, 492-510.

Katsumoto, A., Lu, H., Miranda, A.S., Ransohoff, R.M., 2014. Ontogeny and functions of central nervous system macrophages. J. Immunol. 193, 2615-2621.

Keene, C.D., Cudaback, E., Li, X., Montine, K.S., Montine, T.J., 2011. Apolipoprotein E isoforms and regulation of the innate immune response in brain of patients with Alzheimer's disease. Curr. Opin. Neurobiol. 21, 920-928.

Kipnis, J., Cohen, H., Cardon, M., Ziv, Y., Schwartz, M., 2004. T cell deficiency leads to cognitive dysfunction: implications for therapeutic vaccination for schizophrenia and other psychiatric conditions. Proc. Natl. Acad. Sci. U. S. A. $101,8180-8185$

Klunk, W.E., Engler, H., Nordberg, A., Wang, Y., Blomqvist, G., et al., 2004. Imaging brain amyloid in Alzheimer's disease with Pittsburgh Compound-B. Ann. Neurol. 55, 306-319.

Kobayashi, K., Hayashi, M., Nakano, H., Fukutani, Y., Sasaki, K., et al., 2002. Apoptosis of astrocytes with enhanced lysosomal activity and oligodendrocytes in white matter lesions in Alzheimer's disease. Neuropathol. Appl. Neurobiol. 28, 238-251.

Koller, H., Thiem, K., Siebler, M., 1996. Tumour necrosis factor-alpha increases intracellular $\mathrm{Ca} 2+$ and induces a depolarization in cultured astroglial cells. Brain: J. Neurol. 119 (Pt 6), 2021-2027.

Krauthausen, M., Kummer, M.P., Zimmermann, J., Reyes-Irisarri, E., Terwel, D. et al., 2015. CXCR3 promotes plaque formation and behavioral deficits in an Alzheimer's disease model. J. Clin. Invest. 125, 365-378.
Kunis, G., Baruch, K., Rosenzweig, N., Kertser, A., Miller, O., et al., 2013. IFN-gamma-dependent activation of the brain's choroid plexus for CNS immune surveillance and repair. Brain: J. Neurol. 136, 3427-3440.

Lampron, A., Elali, A., Rivest, S., 2013. Innate immunity in the CNS: redefining the relationship between the CNS and Its environment. Neuron 78, 214-232.

Lee, J.T., Xu, J., Lee, J.M., Ku, G., Han, X., et al., 2004. Amyloid-beta peptide induces oligodendrocyte death by activating the neutral sphingomyelinase-ceramide pathway. J. Cell Biol. 164, 123-131.

Lee, S., Park, J.Y., Lee, W.H., Kim, H., Park, H.C., et al., 2009. Lipocalin-2 is an autocrine mediator of reactive astrocytosis. J. Neurosci. 29, 234-249.

Lee, S., Kim, J.H., Kim, J.H., Seo, J.W., Han, H.S., et al., 2011. Lipocalin-2 Is a chemokine inducer in the central nervous system: role of chemokine ligand 10 (CXCL10) in lipocalin-2-induced cell migration. J. Biol. Chem. 286, $43855-43870$.

Lee, S., Xu, G., Jay, T.R., Bhatta, S., Kim, K.W., et al., 2014. Opposing effects of membrane-anchored CX3CL1 on amyloid and tau pathologies via the p38 MAPK pathway. J. Neurosci. 34, 12538-12546.

Leow-Dyke, S., Allen, C., Denes, A., Nilsson, O., Maysami, S., et al., 2012. Neuronal Toll-like receptor 4 signaling induces brain endothelial activation and neutrophil transmigration in vitro. J. Neuroinflammation 9, 230.

Levy-Lahad, E., Wasco, W., Poorkaj, P., Romano, D.M., Oshima, J., et al., 1995. Candidate gene for the chromosome 1 familial Alzheimer's disease locus. Science 269, 973-977.

Lewis, J., Dickson, D.W., Lin, W.L., Chisholm, L., Corral, A., et al., 2001. Enhanced neurofibrillary degeneration in transgenic mice expressing mutant tau and APP. Science 293, 1487-1491.

Li, M., Shang, D.S., Zhao, W.D., Tian, L., Li, B., et al., 2009. Amyloid beta interaction with receptor for advanced glycation end products up-regulates brain endothelial CCR5 expression and promotes T cells crossing the blood-brain barrier. J. Immunol. 182, 5778-5788.

Liao, M.C., Muratore, C.R., Gierahn, T.M., Sullivan, S.E., Srikanth, P., et al., 2016. Single-cell detection of secreted abeta and sAPPalpha from human IPSC-derived neurons and astrocytes. J. Neurosci. 36, 1730-1746.

Lin, W., Ding, M., Xue, J., Leng, W., 2013. The role of TLR2/JNK/NF-kappaB pathway in amyloid beta peptide-induced inflammatory response in mouse NG108-15 neural cells. Int. Immunopharmacol. 17, 880-884.

Liu, Q., Zerbinatti, C.V., Zhang, J., Hoe, H.S., Wang, B., et al., 2007. Amyloid precursor protein regulates brain apolipoprotein $\mathrm{E}$ and cholesterol metabolism through lipoprotein receptor LRP1. Neuron 56, 66-78.

Liu, Z., Condello, C., Schain, A., Harb, R., Grutzendler, J., 2010. CX3CR1 in microglia regulates brain amyloid deposition through selective protofibrillar amyloid-beta phagocytosis. J. Neurosci. 30, 17091-17101.

Liu, Y.H., Wang, Y.R., Xiang, Y., Zhou, H.D., Giunta, B., et al., 2015. Clearance of amyloid-beta in Alzheimer's disease: shifting the action site from center to periphery. Mol. Neurobiol. 51, 1-7.

Louis, J.C., Magal, E., Takayama, S., Varon, S., 1993. CNTF protection of oligodendrocytes against natural and tumor necrosis factor-induced death. Science 259, 689-692.

Louveau, A., Harris, T.H., Kipnis, J., 2015a. Revisiting the mechanisms of CNS immune privilege. Trends Immunol. 36, 569-577.

Louveau, A., Smirnov, I., Keyes, T.J., Eccles, J.D., Rouhani, S.J., et al., 2015b. Structural and functional features of central nervous system lymphatic vessels. Nature $523,337-341$.

Lucin, K.M., Wyss-Coray, T., 2009. Immune activation in brain aging and neurodegeneration: too much or too little? Neuron 64, 110-122.

Lue, L.F., Walker, D.G., Rogers, J., 2001. Modeling microglial activation in Alzheimer's disease with human postmortem microglial cultures. Neurobiol. Aging 22, 945-956.

Maezawa, I., Nivison, M., Montine, K.S., Maeda, N., Montine, T.J., 2006. Neurotoxicity from innate immune response is greatest with targeted replacement of E4 allele of apolipoprotein E gene and is mediated by microglial p38MAPK. FASEB J. 20, 797-799.

Marques, F., Rodrigues, A.J., Sousa, J.C., Coppola, G., Geschwind, D.H., et al., 2008. Lipocalin 2 is a choroid plexus acute-phase protein. J. Cereb. Blood Flow Metab. $28,450-455$

Marques, F., Sousa, J.C., Coppola, G., Falcao, A.M., Rodrigues, A.J., et al., 2009. Kinetic profile of the transcriptome changes induced in the choroid plexus by peripheral inflammation. J. Cereb. Blood Flow Metab. 29, 921-932.

Marques, F., Sousa, J.C., Sousa, N., Palha, J.A., 2013. Blood-brain-barriers in aging and in Alzheimer's disease. Mol. Neurodegener. 8, 38.

Mawuenyega, K.G., Sigurdson, W., Ovod, V., Munsell, L., Kasten, T., et al., 2010. Decreased clearance of CNS beta-amyloid in Alzheimer's disease. Science 330, 1774.

McGeer, P.L., Itagaki, S., McGeer, E.G., 1988. Expression of the histocompatibility glycoprotein HLA-DR in neurological disease. Acta Neuropathol. (Berl.) 76, 550-557.

McKhann, G.M., Knopman, D.S., Chertkow, H., Hyman, B.T., Jack Jr., C.R., et al., 2011 The diagnosis of dementia due to Alzheimer's disease: recommendations from the National Institute on Aging-Alzheimer's Association workgroups on diagnostic guidelines for Alzheimer's disease. Alzheimers Dement. 7, 263-269.

McManus, R.M., Higgins, S.C., Mills, K.H., Lynch, M.A., 2014. Respiratory infection promotes $\mathrm{T}$ cell infiltration and amyloid-beta deposition in APP/PS1 mice. Neurobiol. Aging 35, 109-121.

Medawar, P.B., 1948. Immunity to homologous grafted skin; the fate of skin homografts transplanted to the brain, to subcutaneous tissue, and to the anterior chamber of the eye. Br. J. Exp. Pathol. 29, 58-69. 
Medeiros, R., LaFerla, F.M., 2013. Astrocytes: conductors of the Alzheimer disease neuroinflammatory symphony. Exp. Neurol. 239, 133-138.

Mesquita, S.D., Ferreira, A.C., Falcao, A.M., Sousa, J.C., Oliveira, T.G., et al., 2014. Lipocalin 2 modulates the cellular response to amyloid beta. Cell Death Differ. $21,1588-1599$

Mesquita, S.D., Ferreira, A.C., Gao, F., Coppola, G., Geschwind, D.H., et al., 2015. The choroid plexus transcriptome reveals changes in type I and II interferon responses in a mouse model of Alzheimer's disease. Brain Behav. Immun. 49, 280-292.

Metcalfe, M.J., Figueiredo-Pereira, M.E., 2010. Relationship between tau pathology and neuroinflammation in Alzheimer's disease. Mount Sinai J. Med. N. Y. 77, $50-58$.

Meyer, E.P., Ulmann-Schuler, A., Staufenbiel, M., Krucker, T., 2008. Altered morphology and 3D architecture of brain vasculature in a mouse model for Alzheimer's disease. Proc. Natl. Acad Sci. U. S. A. 105, 3587-3592.

Meyer-Luehmann, M., Prinz, M., 2015. Myeloid cells in alzheimer's disease: culprits, victims or innocent bystanders? Trends Neurosci. 38 , 659-668.

Meyer-Luehmann, M., Spires-Jones, T.L., Prada, C., Garcia-Alloza, M., de Calignon, A., et al., 2008. Rapid appearance and local toxicity of amyloid-beta plaques in a mouse model of Alzheimer's disease. Nature 451, 720-724.

Michaud, J.P., Bellavance, M.A., Prefontaine, P., Rivest, S., 2013a. Real-time in vivo imaging reveals the ability of monocytes to clear vascular amyloid beta. Cell Rep. 5, 646-653.

Michaud, J.P., Halle, M., Lampron, A., Theriault, P., Prefontaine, P., et al., 2013b. Toll-like receptor 4 stimulation with the detoxified ligand monophosphoryl lipid A improves Alzheimer's disease-related pathology. Proc. Natl. Acad. Sci. U. S. A. $110,1941-1946$.

Mildner, A., Schlevogt, B., Kierdorf, K., Bottcher, C., Erny, D., et al., 2011. Distinct and non-redundant roles of microglia and myeloid subsets in mouse models of Alzheimer's disease. J. Neurosci. 31, 11159-11171.

Mitew, S., Kirkcaldie, M.T., Halliday, G.M., Shepherd, C.E., Vickers, J.C., et al., 2010. Focal demyelination in Alzheimer's disease and transgenic mouse models. Acta Neuropathol. (Berl.) 119, 567-577.

Montine, T.J., Phelps, C.H., Beach, T.G., Bigio, E.H., Cairns, N.J., et al., 2012. National Institute on Aging-Alzheimer's Association guidelines for the neuropathologic assessment of Alzheimer's disease: a practical approach. Acta Neuropathol. (Berl.) 123, 1-11.

Mori, T., Koyama, N., Arendash, G.W., Horikoshi-Sakuraba, Y., Tan, J., et al., 2010. Overexpression of human S100B exacerbates cerebral amyloidosis and gliosis in the Tg2576 mouse model of Alzheimer's disease. Glia 58, 300-314.

Moriyama, M., Fukuhara, T., Britschgi, M., He, Y., Narasimhan, R., et al., 2011. Complement receptor 2 is expressed in neural progenitor cells and regulates adult hippocampal neurogenesis. J. Neurosci. 31, 3981-3989.

Mott, R.T., Ait-Ghezala, G., Town, T., Mori, T., Vendrame, M., et al., 2004. Neuronal expression of CD22: novel mechanism for inhibiting microglial proinflammatory cytokine production. Glia 46, 369-379.

Naert, G., Rivest, S., 2011. CC chemokine receptor 2 deficiency aggravates cognitive impairments and amyloid pathology in a transgenic mouse model of Alzheimer's disease. J. Neurosci. 31, 6208-6220.

Naj, A.C., Jun, G., Beecham, G.W., Wang, L.S., Vardarajan, B.N., et al., 2011. Common variants at MS4A4/MS4A6E, CD2AP, CD33 and EPHA1 are associated with late-onset Alzheimer's disease. Nat. Genet. 43, 436-441.

Naude, P.J., Nyakas, C., Eiden, L.E., Ait-Ali, D., van der Heide, R., et al., 2012. Lipocalin 2: novel component of proinflammatory signaling in Alzheimer's disease. FASEB J. 26, 2811-2823.

Neumann, H., Kotter, M.R., Franklin, R.J., 2009. Debris clearance by microglia: an essential link between degeneration and regeneration. Brain: J. Neurol. 132 , 288-295.

Nimmerjahn, A., Kirchhoff, F., Helmchen, F., 2005. Resting microglial cells are highly dynamic surveillants of brain parenchyma in vivo. Science 308 , 1314-1318.

Oberheim, N.A., Tian, G.F., Han, X., Peng, W., Takano, T., et al., 2008. Loss of astrocytic domain organization in the epileptic brain. J. Neurosci. 28 3264-3276.

Ophir, G., Meilin, S., Efrati, M., Chapman, J., Karussis, D., et al., 2003. Human apoE3 but not apoE4 rescues impaired astrocyte activation in apoE null mice. Neurobiol. Dis. 12, 56-64.

Orre, M., Kamphuis, W., Osborn, L.M., Jansen, A.H., Kooijman, L., et al., 2014. Isolation of glia from Alzheimer's mice reveals inflammation and dysfunction. Neurobiol. Aging 35, 2746-2760.

Oseki, K.T., Monteforte, P.T., Pereira, G.J., Hirata, H., Ureshino, R.P., et al., 2014 Apoptosis induced by Abeta25-35 peptide is $\mathrm{Ca}(2+)$-IP3 signaling-dependent in murine astrocytes. Eur. J. Neurosci. 40, 2471-2478.

Owen, J.A., Punt, J., Stranford, S.A., Jones, P.P., Kuby, J., 2013. Kuby Immunology, 7th ed. W.H. Freeman, New York.

Pan, W., Kastin, A.J., 2002. TNFalpha transport across the blood-brain barrier is abolished in receptor knockout mice. Exp. Neurol. 174, 193-200.

Parajuli, B., Horiuchi, H., Mizuno, T., Takeuchi, H., Suzumura, A., 2015. CCL11 enhances excitotoxic neuronal death by producing reactive oxygen species in microglia. Glia 63, 2274-2284.

Parkhurst, C.N., Yang, G., Ninan, I., Savas, J.N., Yates 3rd, J.R., et al., 2013. Microglia promote learning-dependent synapse formation through brain-derived neurotrophic factor. Cell 155, 1596-1609.

Pekny, M., Pekna, M., 2004. Astrocyte intermediate filaments in CNS pathologies and regeneration. J. Pathol. 204, 428-437.
Pekny, M., Leveen, P., Pekna, M., Eliasson, C., Berthold, C.H., et al., 1995. Mice lacking glial fibrillary acidic protein display astrocytes devoid of intermediate filaments but develop and reproduce normally. EMBO J. 14, 1590-1598.

Perea, G., Navarrete, M., Araque, A., 2009. Tripartite synapses: astrocytes process and control synaptic information. Trends Neurosci. 32, 421-431.

Perrin, R.J., Fagan, A.M., Holtzman, D.M., 2009. Multimodal techniques for diagnosis and prognosis of Alzheimer's disease Nature 461, 916-922.

Perry, R.J., Hodges, J.R., 1999. Attention and executive deficits in Alzheimer's disease: a critical review. Brain: J. Neurol. 122 (Pt 3), 383-404.

Petzold, A., Jenkins, R., Watt, H.C., Green, A.J., Thompson, E.J., et al., 2003. Cerebrospinal fluid S100B correlates with brain atrophy in Alzheimer's disease. Neurosci. Lett. 336, 167-170.

Prince, M., Bryce, R., Albanese, E., Wimo, A., Ribeiro, W., et al., 2013. The global prevalence of dementia: a systematic review and metaanalysis. Alzheimers Dement. 9, 63-75 (e62)

Querfurth, H.W., LaFerla, F.M., 2010. Alzheimer's disease. N. Engl. J. Med. 362, 329-344.

Raj, T., Rothamel, K., Mostafavi, S., Ye, C., Lee, M.N., et al., 2014. Polarization of the effects of autoimmune and neurodegenerative risk alleles in leukocytes. Science 344, 519-523.

Ramirez, G., Toro, R., Dobeli, H., von Bernhardi, R., 2005. Protection of rat primary hippocampal cultures from A beta cytotoxicity by pro-inflammatory molecules is mediated by astrocytes. Neurobiol. Dis. 19, 243-254.

Ransohoff, R.M., Perry, V.H., 2009. Microglial physiology: unique stimuli, specialized responses. Annu. Rev. Immunol. 27, 119-145.

Ransohoff, R.M., 2009. Chemokines and chemokine receptors: standing at the crossroads of immunobiology and neurobiology. Immunity 31, 711-721.

Ransohoff, R.M., 2011. Ageing: blood ties. Nature 477, 41-42.

Reed-Geaghan, E.G., Savage, J.C., Hise, A.G., Landreth, G.E., 2009. CD14 and toll-like receptors 2 and 4 are required for fibrillar $A\{$ beta $\}$-stimulated microglial activation. J. Neurosci. 29, 11982-11992.

Rezaie, P., Male, D., 2002. Mesoglia \& microglia-a historical review of the concept of mononuclear phagocytes within the central nervous system. J. Hist. Neurosci. 11, 325-374.

Richard, K.L., Filali, M., Prefontaine, P., Rivest, S., 2008. Toll-like receptor 2 acts as a natural innate immune receptor to clear amyloid beta 1-42 and delay the cognitive decline in a mouse model of Alzheimer's disease. J. Neurosci. 28, 5784-5793.

Roberson, E.D., Mucke, L., 2006. 100 years and counting: prospects for defeating Alzheimer's disease. Science 314, 781-784.

Rogers, J., Luber-Narod, J., Styren, S.D., Civin, W.H., 1988. Expression of immune system-associated antigens by cells of the human central nervous system: relationship to the pathology of Alzheimer's disease. Neurobiol. Aging 9, 339-349.

Roth, A.D., Ramirez, G., Alarcon, R., Von Bernhardi, R., 2005. Oligodendrocytes damage in Alzheimer's disease: beta amyloid toxicity and inflammation. Biol. Res. 38, 381-387.

Rothstein, J.D., Dykes-Hoberg, M., Pardo, C.A., Bristol, L.A., Jin, L., et al., 1996 Knockout of glutamate transporters reveals a major role for astroglial transport in excitotoxicity and clearance of glutamate. Neuron 16,675-686.

Roudkenar, M.H., Halabian, R., Bahmani, P., Roushandeh, A.M., Kuwahara, Y., et al., 2011. Neutrophil gelatinase-associated lipocalin: a new antioxidant that exerts its cytoprotective effect independent on Heme Oxygenase-1. Free Radic. Res. $45,810-819$.

Roussos, P., Katsel, P., Fam, P., Tan, W., Purohit, D.P., et al., 2014. The triggering receptor expressed on myeloid cells 2 (TREM2) is associated with enhanced inflammation, neuropathological lesions and increased risk for Alzheimer's dementia. Alzheimers Dement. 11, 1163-1170.

Sagare, A.P., Bell, R.D., Zhao, Z., Ma, Q., Winkler, E.A., et al., 2013. Pericyte loss influences Alzheimer-like neurodegeneration in mice. Nat. Commun. 4, 2932

Schellenberg, G.D., Bird, T.D., Wijsman, E.M., Orr, H.T., Anderson, L., et al., 1992. Genetic linkage evidence for a familial Alzheimer's disease locus on chromosome 14. Science 258, 668-671.

Schenk, D., Barbour, R., Dunn, W., Gordon, G., Grajeda, H., et al., 1999. Immunization with amyloid-beta attenuates Alzheimer-disease-like pathology in the PDAPP mouse. Nature 400, 173-177.

Scholtzova, H., Kascsak, R.J., Bates, K.A., Boutajangout, A., Kerr, D.J., et al., 2009. Induction of toll-like receptor 9 signaling as a method for ameliorating Alzheimer's disease-related pathology. J. Neurosci. 29, 1846-1854.

Schummers, J., Yu, H., Sur, M., 2008. Tuned responses of astrocytes and their influence on hemodynamic signals in the visual cortex. Science 320 , 1638-1643.

Schwartz, M., Baruch, K., 2014a. Breaking peripheral immune tolerance to CNS antigens in neurodegenerative diseases: boosting autoimmunity to fight-off chronic neuroinflammation. J. Autoimmun. 54, 8-14.

Schwartz, M., Baruch, K., 2014b. The resolution of neuroinflammation in neurodegeneration: leukocyte recruitment via the choroid plexus. EMBO J. 33, 7-22.

Schwartz, M., Kipnis, J., Rivest, S., Prat, A., 2013. How do immune cells support and shape the brain in health, disease, and aging? J. Neurosci. 33, 17587-17596.

Sengillo, J.D., Winkler, E.A., Walker, C.T., Sullivan, J.S., Johnson, M., et al., 2013. Deficiency in mural vascular cells coincides with blood-brain barrier disruption in Alzheimer's disease. Brain Pathol. 23, 303-310.

Shechter, R., Miller, O., Yovel, G., Rosenzweig, N., London, A., et al., 2013. Recruitment of beneficial M2 macrophages to injured spinal cord is orchestrated by remote brain choroid plexus. Immunity 38, 555-569. 
Shibata, M., Yamada, S., Kumar, S.R., Calero, M., Bading, J., et al., 2000. Clearance of Alzheimer's amyloid-ss(1-40) peptide from brain by LDL receptor-related protein-1 at the blood-brain barrier. J. Clin. Invest. 106, 1489-1499.

Shigetomi, E., Bowser, D.N., Sofroniew, M.V., Khakh, B.S., 2008. Two forms of astrocyte calcium excitability have distinct effects on NMDA receptor-mediated slow inward currents in pyramidal neurons. J. Neurosci. 28, 6659-6663.

Shigetomi, E., Kracun, S., Sofroniew, M.V., Khakh, B.S., 2010. A genetically targeted optical sensor to monitor calcium signals in astrocyte processes. Nat. Neurosci. $13,759-766$.

Simard, A.R., Soulet, D., Gowing, G., Julien, J.P., Rivest, S., 2006. Bone marrow-derived microglia play a critical role in restricting senile plaque formation in Alzheimer's disease. Neuron 49, 489-502.

Sofroniew, M.V., Vinters, H.V., 2010. Astrocytes: biology and pathology. Acta Neuropathol. (Berl.) 119, 7-35

Sperling, R.A., Aisen, P.S., Beckett, L.A., Bennett, D.A., Craft, S., et al., 2011. Toward defining the preclinical stages of Alzheimer's disease: recommendations from the National Institute on Aging-Alzheimer's Association workgroups on diagnostic guidelines for Alzheimer's disease. Alzheimers Dement. 7, 280-292.

Stalder, A.K., Ermini, F., Bondolfi, L., Krenger, W., Burbach, G.J., et al., 2005. Invasion of hematopoietic cells into the brain of amyloid precursor protein transgenic mice. J. Neurosci. 25, 11125-11132.

Stolp, H.B., Liddelow, S.A., Sa-Pereira, I., Dziegielewska, K.M., Saunders, N.R., 2013. Immune responses at brain barriers and implications for brain development and neurological function in later life. Front. Integr. Neurosci. 7, 61

Suzuki, N., Cheung, T.T., Cai, X.D., Odaka, A., Otvos Jr., L., et al., 1994. An increased percentage of long amyloid beta protein secreted by familial amyloid beta protein precursor (beta APP717) mutants. Science 264, 1336-1340.

Takahashi, K., Rochford, C.D., Neumann, H., 2005. Clearance of apoptotic neurons without inflammation by microglial triggering receptor expressed on myeloid cells-2. J. Exp. Med. 201, 647-657.

Taylor, J.M., Minter, M.R., Newman, A.G., Zhang, M., Adlard, P.A., et al., 2014. Type-1 interferon signaling mediates neuro-inflammatory events in models of Alzheimer's disease. Neurobiol. Aging 35, 1012-1023.

Tigges, U., Boroujerdi, A., Welser-Alves, J.V., Milner, R., 2013. TNF-alpha promotes cerebral pericyte remodeling in vitro, via a switch from alpha1 to alpha2 integrins. J. Neuroinflammation 10, 33.

Town, T., Vendrame, M., Patel, A., Poetter, D., DelleDonne, A., et al., 2002. Reduced Th1 and enhanced Th2 immunity after immunization with Alzheimer's beta-amyloid(1-42). J. Neuroimmunol. 132, 49-59.

Town, T., Laouar, Y., Pittenger, C., Mori, T., Szekely, C.A., et al., 2008. Blocking TGF-beta-Smad2/3 innate immune signaling mitigates Alzheimer-like pathology. Nat. Med. 14, 681-687.

Tripathy, D., Thirumangalakudi, L., Grammas, P., 2010. RANTES upregulation in the Alzheimer's disease brain: a possible neuroprotective role. Neurobiol. Aging $31,8-16$.

Ueno, M., Fujita, Y., Tanaka, T., Nakamura, Y., Kikuta, J., et al., 2013. Layer V cortical neurons require microglial support for survival during postnatal development. Nat. Neurosci. 16, 543-551.

Ullian, E.M., Sapperstein, S.K., Christopherson, K.S., Barres, B.A., 2001. Control of synapse number by glia. Science 291, 657-661.

Vargas, T., Ugalde, C., Spuch, C., Antequera, D., Moran, M.J., et al., 2010. Abeta accumulation in choroid plexus is associated with mitochondrial-induced apoptosis. Neurobiol. Aging 31, 1569-1581.

Varvel, N.H., Grathwohl, S.A., Baumann, F., Liebig, C., Bosch, A., et al., 2012. Microglial repopulation model reveals a robust homeostatic process for replacing CNS myeloid cells. Proc. Natl. Acad. Sci. U. S. A. 109, 18150-18155.

Veeraraghavalu, K., Zhang, C., Zhang, X., Tanzi, R.E., Sisodia, S.S., 2014. Age-dependent, non-cell-autonomous deposition of amyloid from synthesis of beta-amyloid by cells other than excitatory neurons. J. Neurosci. 34 3668-3673.

Villeda, S.A., Luo, J., Mosher, K.I., Zou, B., Britschgi, M., et al., 2011. The ageing systemic milieu negatively regulates neurogenesis and cognitive function. Nature 477, 90-94.

Villeda, S.A., Plambeck, K.E., Middeldorp, J., Castellano, J.M., Mosher, K.I., et al., 2014. Young blood reverses age-related impairments in cognitive function and synaptic plasticity in mice. Nat. Med. 20, 659-663.

Villemagne, V.L., Perez, K.A., Pike, K.E., Kok, W.M., Rowe, C.C., et al., 2010. Blood-borne amyloid-beta dimer correlates with clinical markers of Alzheimer's disease. J. Neurosci. 30, 6315-6322.

Vitek, M.P., Brown, C.M., Colton, C.A., 2009. APOE genotype-specific differences in the innate immune response. Neurobiol. Aging 30, 1350-1360.

Vom Berg, J., Prokop, S., Miller, K.R., Obst, J., Kalin, R.E., et al., 2012. Inhibition of IL-12/IL-23 signaling reduces Alzheimer's disease-like pathology and cognitive decline. Nat. Med. 18, 1812-1819.

Voskuhl, R.R., Peterson, R.S., Song, B., Ao, Y., Morales, L.B., et al., 2009. Reactive astrocytes form scar-like perivascular barriers to leukocytes during adaptive immune inflammation of the CNS. J. Neurosci. 29, 11511-11522.
WHO, 2015. World Report on Ageing and Health. World Health Organization, Geneva, Switzerland.

Wake, H., Moorhouse, A.J., Jinno, S., Kohsaka, S., Nabekura, J., 2009. Resting microglia directly monitor the functional state of synapses in vivo and determine the fate of ischemic terminals. J. Neurosci. 29, 3974-3980.

Walker, D.G., Kim, S.U., McGeer, P.L., 1995. Complement and cytokine gene expression in cultured microglial derived from postmortem human brains. J. Neurosci. Res. 40, 478-493.

Walker, D.G., Lue, L.F., Beach, T.G., 2001. Gene expression profiling of amyloid beta peptide-stimulated human post-mortem brain microglia. Neurobiol. Aging 22, 957-966.

Walker, D.G., Dalsing-Hernandez, J.E., Campbell, N.A., Lue, L.F., 2009. Decreased expression of CD200 and CD200 receptor in Alzheimer's disease: a potential mechanism leading to chronic inflammation. Exp. Neurol. 215, 5-19.

Walton, N.M., Sutter, B.M., Laywell, E.D., Levkoff, L.H., Kearns, S.M., et al., 2006 Microglia instruct subventricular zone neurogenesis. Glia 54, 815-825.

Webster, S.J., Bachstetter, A.D., Nelson, P.T., Schmitt, F.A., Van Eldik, L.J., 2014 Using mice to model Alzheimer's dementia: an overview of the clinical disease and the preclinical behavioral changes in 10 mouse models. Front. Genet. 5, 88.

Weekman, E.M., Sudduth, T.L., Abner, E.L., Popa, G.J., Mendenhall, M.D., et al., 2014 Transition from an M1 to a mixed neuroinflammatory phenotype increases amyloid deposition in APP/PS1 transgenic mice. J. Neuroinflammation 11, 127.

Weiner, H.L., Frenkel, D., 2006. Immunology and immunotherapy of Alzheimer's disease. Nat. Rev. Immunol. 6, 404-416.

Weiss, R., Lifshitz, V., Frenkel, D., 2011. TGF-beta1 affects endothelial cell interaction with macrophages and T cells leading to the development of cerebrovascular amyloidosis. Brain Behav. Immun. 25, 1017-1024.

Wes, P.D., Easton, A., Corradi, J., Barten, D.M., Devidze, N., et al., 2014. Tau overexpression impacts a neuroinflammation gene expression network perturbed in Alzheimer's disease. PLoS One 9, e106050.

White, J.A., Manelli, A.M., Holmberg, K.H., Van Eldik, L.J., Ladu, M.J., 2005 Differential effects of oligomeric and fibrillar amyloid-beta 1-42 on astrocyte-mediated inflammation. Neurobiol. Dis. 18, 459-465.

Wolburg, H., Paulus, W., 2010. Choroid plexus: biology and pathology. Acta Neuropathol. (Berl.) 119, 75-88.

Wolburg, H., Wolburg-Buchholz, K., Liebner, S., Engelhardt, B., 2001. Claudin-1, claudin-2 and claudin-11 are present in tight junctions of choroid plexus epithelium of the mouse. Neurosci. Lett. 307, 77-80.

Wolfe, M.S., Xia, W., Ostaszewski, B.L., Diehl, T.S., Kimberly, W.T., et al., 1999. Two transmembrane aspartates in presenilin-1 required for presenilin endoproteolysis and gamma-secretase activity. Nature 398, 513-517.

Wyss-Coray, T., Lin, C., Yan, F., Yu, G.Q., Rohde, M., et al., 2001. TGF-beta1 promotes microglial amyloid-beta clearance and reduces plaque burden in transgenic mice. Nat. Med. 7, 612-618.

Wyss-Coray, T., Yan, F., Lin, A.H., Lambris, J.D., Alexander, J.J., et al., 2002. Prominent neurodegeneration and increased plaque formation in complement-inhibited Alzheimer's mice. Proc. Natl. Acad. Sci. U. S. A. 99, 10837-10842.

Wyss-Coray, T., Loike, J.D., Brionne, T.C., Lu, E., Anankov, R., et al., 2003. Adult mouse astrocytes degrade amyloid-beta in vitro and in situ. Nat. Med. 9, 453-457.

Wyss-Coray, T., 2006. Inflammation in Alzheimer disease: driving force, bystander or beneficial response? Nat. Med. 12, 1005-1015.

Xu, J., Chen, S., Ahmed, S.H., Chen, H., Ku, G., et al., 2001. Amyloid-beta peptides are cytotoxic to oligodendrocytes. J. Neurosci. 21, RC118.

Xu, Y.Z., Nygard, M., Kristensson, K., Bentivoglio, M., 2010. Regulation of cytokine signaling and T-cell recruitment in the aging mouse brain in response to central inflammatory challenge. Brain Behav. Immun. 24, 138-152.

Yan, S.D., Chen, X., Fu, J., Chen, M., Zhu, H., et al., 1996. RAGE and amyloid-beta peptide neurotoxicity in Alzheimer's disease. Nature 382, 685-691.

Zeng, C., Lee, J.T., Chen, H., Chen, S., Hsu, C.Y., et al., 2005. Amyloid-beta peptide enhances tumor necrosis factor-alpha-induced iNOS through neutral sphingomyelinase/ceramide pathway in oligodendrocytes. J. Neurochem. 94 703-712.

Zhang, G., Li, J., Purkayastha, S., Tang, Y., Zhang, H., et al., 2013. Hypothalamic programming of systemic ageing involving IKK-beta, NF-kappaB and GnRH. Nature 497, 211-216.

Zhu, Y., Obregon, D., Hou, H., Giunta, B., Ehrhart, J., et al., 2011. Mutant presenilin-1 deregulated peripheral immunity exacerbates Alzheimer-like pathology. J. Cell. Mol. Med. 15, 327-338.

Zlokovic, B.V., 2008. The blood-brain barrier in health and chronic neurodegenerative disorders. Neuron 57, 178-201.

Zlokovic, B.V., 2013. Cerebrovascular effects of apolipoprotein E: implications for Alzheimer disease. JAMA neurology 70, 440-444. 